\title{
Maternal Immunization: Nature Meets Nurture
}

\author{
Anja Saso ${ }^{1,2}$ and Beate Kampmann ${ }^{1,2 *}$ \\ ' Faculty of Infectious and Tropical Diseases, London School of Hygiene \& Tropical Medicine, London, United Kingdom, \\ 2 Vaccines and Immunity Theme, MRC Unit The Gambia at LSHTM, Banjul, Gambia
}

OPEN ACCESS

Edited by:

David B. Weiner,

University of Pennsylvania,

United States

Reviewed by:

William Horsnell,

University of Cape Town, South Africa

Sallie Permar,

Duke University, United States

*Correspondence:

Beate Kampmann

Beate.Kampmann@lshtm.ac.uk;

bkampmann@mrc.gm

Specialty section:

This article was submitted to

Infectious Diseases,

a section of the journal

Frontiers in Microbiology

Received: 31 January 2020

Accepted: 09 June 2020

Published: 24 July 2020

Citation:

Saso A and Kampmann B (2020)

Maternal Immunization: Nature Meets

Nurture. Front. Microbiol. 11:1499.

doi: 10.3389/fmicb.2020.01499
Vaccinating women in pregnancy (i.e., maternal immunization) has emerged as a promising tool to tackle infant morbidity and mortality worldwide. This approach nurtures a 'gift of nature,' whereby antibody is transferred from mother to fetus transplacentally during pregnancy, or postnatally in breast milk, thereby providing passive, antigenspecific protection against infections in the first few months of life, a period of increased immune vulnerability for the infant. In this review, we briefly summarize the rationale for maternal immunization programs and the landscape of vaccines currently in use or in the pipeline. We then direct the focus to the underlying biological phenomena, including the main mechanisms by which maternally derived antibody is transferred efficiently to the infant, at the placental interface or in breast milk; important research models and methodological approaches to interrogate these processes, particularly in the context of recent advances in systems vaccinology; the potential biological and clinical impact of high maternal antibody titres on neonatal ontogeny and subsequent infant vaccine responses; and key vaccine- and host-related factors influencing the maternal-infant dyad across different environments. Finally, we outline important gaps in knowledge and suggest future avenues of research on this topic, proposing potential strategies to ensure optimal testing, delivery and implementation of maternal vaccination programs worldwide.

Keywords: maternal immunization, vaccine, neonate, infant immunity, placenta, antibody, breast milk

\section{INTRODUCTION}

To improve maternal and neonatal health remains a focus of international investment in global health, given that Millenium Goals 4 and 5 were not achieved (Victora et al., 2016). Despite the wider roll-out and availability of vaccines through the Expanded Program of Immunization (EPI) and their significant contribution to the reduction in under-5 morbidity and mortality, there remains a large gap in protection from infectious diseases in newborns: $40 \%$ of all mortality in children under the age of 5 now falls into the neonatal period, a third is attributable to potentially preventable infections. This has significant impact on economic development and welfare of the populations affected, primarily in low- and middle-income countries (LMICs) (Liu et al., 2016).

\section{CAN WE ACHIEVE EVEN MORE WITH VACCINES?}

There is increasing momentum to develop and implement vaccination of women during pregnancy (also called maternal immunization) to prevent specific infections of particular relevance to pregnancy and the newborn (Zaman et al., 2008; Lindsey et al., 2012; Saso and Kampmann, 2016; 
Switzer et al., 2019). This approach nurtures a 'gift of nature,' whereby antibody is transferred from mother to fetus during pregnancy, via the placenta or postnatally in breast milk, in order to provide passive protection against pathogens in the first few months of life. Maternal immunization, therefore, enhances this passive protection, targeting specific antigens.

Two broad aims can be achieved: (1) Pregnant women can be protected against a number of infectious diseases with more severe outcomes in pregnancy (e.g., influenza) and (2) their newborn babies are protected by high titres of antigenspecific IgG antibody against diseases of particular importance in the newborn [e.g., tetanus, pertussis, Group B streptococcus (GBS), Respiratory Syncytial Virus (RSV)] due to their associated susceptibility (e.g., GBS, tetanus) or severity (e.g., pertussis, RSV) and until they develop protective antibody after receiving their own vaccines or following natural exposure.

Depending on geographical location, maternal immunization is already routinely recommended to prevent tetanus, pertussis and influenza with proven safety, immunogenicity and efficacy, but uptake and coverage vary widely (Lindsey et al., 2012; WHO: Global Advisory Committee on Vaccine Safety, 2014; Steedman et al., 2016; Gkentzi et al., 2017; Marchant et al., 2017; Munoz and Jamieson, 2019; Wales et al., 2020). New vaccines for explicit use in pregnancy are likely to become available in the next few years. However, a number of biological and implementation challenges remain to be addressed to harness the full potential of this intervention. In this review, we summarize key knowledge and identify important gaps in our understanding of vaccination in pregnancy and its impact on the neonatal immune system. We deliberately focus on biological opportunities and challenges, and we will briefly address the nevertheless considerable challenges to implementation of this promising intervention.

\section{WHAT IS MATERNAL IMMUNIZATION?}

Every pregnant woman passes on antibody to her unborn child via the placenta and through this pregnancy-associated natural phenomenon provides passive protection against a range of pathogens, simply as a 'gift of nature.' In a sense, each pregnant woman already naturally 'immunizes' her unborn child during the pregnancy, in order to protect it from pathogens during the first few months of life, as it transitions from the relatively sterile in utero setting to the new reality of an environment full of germs: some hostile, some not. The principle of maternal immunization essentially represents the augmentation of specific antibodies against organisms of high pathogenicity to the newborn, throughout this period of significant immune vulnerability; actively immunizing a mother during her pregnancy capitalizes on the indirect protection that will already be conferred to her newborn, thereby combining nature with nurture (Munoz and Jamieson, 2019; Jarvis et al., 2020). Maternal vaccines also have the potential to protect against congenital transmission of pathogens and viral seeding of the placenta, a strategy currently being explored primarily in the context of cytomegalovirus (CMV) (Schleiss et al., 2017; Permar et al., 2018) and herpes simplex virus (HSV) (Okala et al., 2019; Patel et al., 2019a,
2020). Risk of intrauterine viral transmission is generally higher if primary infection occurs during pregnancy, indicating that fetal protection is likely achieved through transplacental transfer of neutralizing maternal antibodies.

Table 1 briefly summarizes the vaccines recommended for (A) routine use in pregnancy, (B) use in emergencies and outbreak situations and $(\mathrm{C})$ vaccines in advanced clinical development.

\section{WHAT DO WE KNOW ABOUT VACCINE RESPONSES IN PREGNANCY AND MATERNAL ANTIBODY TRANSFER?}

\section{Mechanism of Transplacental Transfer}

The human feto-maternal interface is complex and unique but remains incompletely understood. Immune interactions are tightly controlled in order to establish a favorable immunological environment for the developing fetus which expresses 'foreign' paternal antigens with the potential to activate the maternal immune system; given this, regulatory mechanisms are induced that effectively promote immunological tolerance (Jennewein et al., 2017; Than et al., 2019).

In particular, the placenta acts as an important physical and biochemical/immunological barrier between maternal and fetal circulations. It consists of the chorionic villous unit: multinucleated syncytiotrophoblast (in direct contact with maternal blood), the villous stroma and the fetal capillary endothelium. Signaling across the placenta is now considered to be bidirectional, involving both active and passive mechanisms, with a potentially significant role played by extracellular vesicles and seeding of genetically foreign maternal and fetal cells, closely regulated throughout pregnancy to ensure optimal fetal growth and development (Holder et al., 2016; Rice et al., 2018).

Maternal immunoglobulin G (IgG) is transported across the placenta from around 13-weeks' gestation and provides passive protection to the infant in the early, most vulnerable postnatal period, prior to initiation of the primary immunization schedule (Simister, 2003; Edwards, 2015). It is an active, pHdependent process, predominantly mediated through binding of the IgG Fc portion to the neonatal Fc receptor $(\mathrm{FcRn})$ in the placental syncytiotrophoblast (van den Berg et al., 2010; Palmeira and Carneiro-Sampaio, 2016; Pyzik et al., 2019). This interaction is unique, and its significance has only recently been established (Roopenian and Akilesh, 2007; Rath et al., 2013; Jennewein et al., 2017).

Unlike syncytiotrophoblast cells, stroma or fetal endothelium appears not to express FcRn and, therefore, the mechanisms underlying the onward transport of IgG beyond the syncytiotrophoblast require further exploration; alternative non-canonical Fc $\gamma$ receptors, such as Fc $\gamma$ RI/RII/RIII, are known to be expressed by these final placental layers and may play a key role (Simister, 2003; Martinez et al., 2018).

In some cases, however, maternal IgG may facilitate vertical pathogen transmission, by forming antibody-antigen complexes which are transported across the syncytiotrophoblast via FcRn and epidermal growth factor receptor (EGFR) 
TABLE 1 | Summary of vaccines recommended by WHO for $\mathbf{( A )}$ routine use by national programs, (B) use in emergencies or outbreak situations, and (C) in advanced clinical development.

\begin{tabular}{|c|c|c|}
\hline Disease & Vaccine type & Recommendation \\
\hline \multicolumn{3}{|c|}{ (A) Routinely recommended vaccines for pregnant women } \\
\hline Tetanus & Toxoid & $\begin{array}{l}\text { Tetanus toxoid vaccination is recommended for all pregnant women, depending on previous } \\
\text { tetanus vaccination exposure, to prevent neonatal mortality from tetanus (World Health } \\
\text { Organization, 2018c). }\end{array}$ \\
\hline Influenza A & Inactivated & $\begin{array}{l}\text { WHO recommends seasonal influenza vaccination to pregnant women as the highest priority (World } \\
\text { Health Organization, 2020). }\end{array}$ \\
\hline Pertussis & Subunit adjuvanted & $\begin{array}{l}\text { Vaccination of pregnant women is likely to be the most cost-effective additional strategy for } \\
\text { preventing pertussis disease in infants too young to be vaccinated (World Health Organization, } \\
2016 b) \text {. }\end{array}$ \\
\hline \multicolumn{3}{|c|}{ (B) Vaccines specifically recommended in endemic countries or during outbreaks } \\
\hline Cholera & Inactivated & $\begin{array}{l}\text { Pregnant and lactating women should be included in Oral Cholera Vaccine campaigns. Evidence } \\
\text { indicates high potential benefit and minimal risks (Moro and Sukumaran, 2017; World Health } \\
\text { Organization, 2018a). }\end{array}$ \\
\hline Ebola & $\begin{array}{l}\text { Non-replicating or } \\
\text { replication-deficient }\end{array}$ & $\begin{array}{l}\text { Since the three new candidate vaccines are non-replicating or replication deficient, pregnant and } \\
\text { lactating women should be included into the clinical trial protocols (UN News, 2019; Sage Interim } \\
\text { Recommendations on Vaccination against Ebola Virus Disease, 2019). }\end{array}$ \\
\hline Hepatitis E & $\begin{array}{l}\text { Recombinant, } \\
\text { adjuvanted }\end{array}$ & $\begin{array}{l}\text { The use of the vaccine to reduce or prevent outbreaks of hepatitis E should be considered as well } \\
\text { its use to mitigate consequences in high risk groups such as pregnant women (World Health } \\
\text { Organization, 2016a). }\end{array}$ \\
\hline Meningitis A (MenA) & Conjugated & $\begin{array}{l}\text { Pregnant and lactating women residing in the meningitis belt receive the MenA conjugate vaccine } \\
\text { during any stage of pregnancy or lactation (World Health Organization, 2018d). }\end{array}$ \\
\hline Rabies & Inactivated & $\begin{array}{l}\text { Rabies vaccines and rabies Immunoglobulin are safe and effective in pregnant and lactating women } \\
\text { (World Health Organization, 2018b). }\end{array}$ \\
\hline Tick-borne encephalitis & Inactivated & $\begin{array}{l}\text { The vaccine should be used in pregnant women who live in areas where the incidence of the } \\
\text { disease is high ( }>5 \text { cases/100,000 population per year) (World Health Organization, 2011). }\end{array}$ \\
\hline Yellow Fever (YF) & Live attenuated & $\begin{array}{l}\text { In areas where YF is endemic, or during outbreaks, the benefits of YF vaccination are likely to far } \\
\text { outweigh the risk of potential transmission of vaccine-related virus to the fetus or infant (World } \\
\text { Health Organization, 2015). }\end{array}$ \\
\hline \multicolumn{3}{|c|}{ (C) Vaccines for specific use in pregnancy and in advanced clinical trials but not yet licensed or pre-qualified } \\
\hline Group B streptococcus (GBS) & Conjugated & $\begin{array}{l}\text { For exclusive use in pregnancy to prevent early and late onset GBS infection in the neonate, } \\
\text { potential impact on premature birth and stillbirths, several candidates under development. } \\
\text { For GBS vaccine research and development technical roadmap and WHO Preferred Product } \\
\text { Characteristics please see } \\
\text { https://www.who.int/immunization/research/development/ppc_groupb_strepvaccines/en/ }\end{array}$ \\
\hline Respiratory Syncytial Virus (RSV) & $\begin{array}{l}\text { Subunit }+/- \\
\text { adjuvanted }\end{array}$ & $\begin{array}{l}\text { To prevent severe RSV disease in young infants, several candidates under development. For priority } \\
\text { activities for development, testing, licensure and global use of RSV vaccines, with a specific focus } \\
\text { on the medical need for young children in low- and middle-income countries please see: } \\
\text { https://www.who.int/immunization/research/development/ppc_rsv_vaccines/en/ }\end{array}$ \\
\hline
\end{tabular}

*Most WHO vaccine position papers are easily accessible via this link: https://www.who.int/immunization/documents/positionpapers/en/.

(Pereira and Maidji, 2008). Congenital CMV risk, for example, is greatest in the third trimester, potentially correlating with highest expression of FcRn and EGFR (and hence peak of transplacental IgG transfer). Further assessment using an ex vivo human placental model demonstrated that the functionality of CMV antibody may play a significant role: weakly neutralizing compared to potently neutralizing monoclonal IgG facilitated placental CMV infection (Maidji et al., 2006; Permar et al., 2018).

\section{Mechanism of Antibody Transfer Through Breast Milk}

After birth, the placental barrier protection is replaced by the mammary gland barrier. The specific antibodies generated are also secreted into breast milk (primarily colostrum) with secretory $\operatorname{IgA}(\operatorname{sg} \mathrm{A})$ as the predominant antibody class, and transferred orally to infants during lactation (Schlaudecker et al., 2013; Abu Raya et al., 2014; Maertens et al., 2014; De Schutter et al., 2015). IgA is transported across alveolar epithelial cells by the polymeric Ig receptor (pIgR) and released at the apical surface (Palmeira and Carneiro-Sampaio, 2016; Jennewein et al., 2017). The extracellular domain of pIgR is the secretory component which is covalently attached to IgA, protecting it from degradation by host and microbial proteases. IgA also binds to Fc alpha receptor on the surface of myeloid cells (Aleyd et al., 2015). Recent preliminary findings, in the context of 13valent pneumococcal conjugate vaccine given during pregnancy, also suggest that breast milk antibodies, boosted by maternal immunization, may impact the presence of vaccine antigenspecific memory B cells in Colostrum (Munoz et al., 2018).

By preventing epithelial adhesion and neutralizing toxins or virulence factors, $\operatorname{sg} A$ inhibits invasion and damage from pathogens at mucosal surfaces (Maertens et al., 2014; 
Edwards, 2015). Interestingly, sIgA does not activate the complement cascade, contributing to anti-inflammatory benefits of breast feeding. As well as passive protection, breast milk is now considered to have an active immunomodulatory effect, promoting gut barrier homeostasis and microbiome maturation, helping to establish immune tolerance in the early postnatal period, and potentially shaping systemic infant responses; many details, however, particularly the contribution of sIgA, are still poorly understood (Oddy, 2002; Andreas et al., 2015).

\section{Factors Affecting Maternal Antibody Transfer Across the Placenta}

In general, given the usual half-life of immunoglobulins, higher maternal and cord antigen-specific IgG concentrations are associated with subsequently longer, more effective protection in the infant in early life (Palmeira et al., 2012; Niewiesk, 2014; Fouda et al., 2018). The aim of maternal immunization is, therefore, to boost these levels well above the putative threshold of protection. Both intrinsic and extrinsic factors play a role in regulating production of adequate titres of initial maternal antibody but also its subsequent efficient transfer across the placenta. Emerging data suggests this may be selective and differentially mediated (Marchant et al., 2017; Wilcox et al., 2017). Determining the mechanisms that regulate IgG Fc-mediated functional activity at the placental interface will enable optimization of maternal vaccines in the future (Mahan et al., 2016).

\section{IgG Subclass}

IgG characteristics that impact FcRn interactions play a role in placental IgG transfer efficiency (Palmeira et al., 2012; Lozano et al., 2018). The IgG subclass distribution across different antigen-specific IgG populations is distinct and modulates their placental transfer efficiency, as previously demonstrated for pertussis, diphtheria, tetanus, Haemophilus influenzae type $B$ (HiB), Neisseria meningitidis $\mathrm{C}$ and varicella zoster virus (VZV) (van den Berg et al., 2010; Vidarsson et al., 2014; Martinez et al., 2019). Specifically, IgG1 is most efficiently transferred, followed by IgG3 and IgG4, in comparison to IgG2 which is significantly reduced (Einarsdottir et al., 2014; Vidarsson et al., 2014). One contributing factor to these differences may be the IgG hinge region, which varies in its length and flexibility across subclasses, potentially impacting the orientation and movement of the Fab arms relative to the Fc tail (Vidarsson et al., 2014; Abdiche et al., 2015). It has also been reported that individual receptor types (FcRn vs. Fc $\gamma$ RII vs. Fc $\gamma$ RIII) may vary in their affinity and specificity for different IgG subclasses (Bruhns et al., 2009).

\section{IgG Antigen-Specificity}

Placental transfer is distinctly influenced by different antigenspecific IgG populations (van den Berg et al., 2010; Palmeira et al., 2012). Vaccines that contain protein antigens, such as tetanus toxoid or pertussis toxin, are transferred more efficiently than polysaccharide vaccines, including $\mathrm{HiB}$ and pneumococcus. The basis for this difference is unknown but may be related, in part, to subclass, given that protein antigens predominantly elicit IgG1 and IgG3 secretion, while IgG2 is more critical for the opsonisation and killing of polysaccharide-encapsulated pathogens (Vidarsson et al., 2014).

\section{IgG Glycosylation}

IgG exists in a number of glycosylated variants, which have undergone covalent addition of different sugar moieties and may vary in their kinetics, binding affinity to different placental Fc receptors, efficiency of transplacental transfer and functionality (Lofano et al., 2018; Jennewein et al., 2019). Fc region fucose glycans, for example, have been shown to mediate binding strength to FcyRIIIa in vitro (Okazaki et al., 2004; Mahan et al., 2016). Importantly, different vaccines and/or infective pathogens elicit distinct antigen-specific IgG Fc region glycan profiles (Mahan et al., 2014, 2016; Vestrheim et al., 2014). Therefore, while subclass selection alters the Fc domain irreversibly, modifying antibody glycosylation provides a more flexible mechanism by which the humoral compartment streamlines antibody effector function to effectively target a particular pathogen (Vestrheim et al., 2014; Mahan et al., 2016; Alter et al., 2018).

A recent study used an unbiased, systems serology approach (Chung and Alter, 2017) to evaluate differences in qualitative antigen-specific Fc-profiles between maternal and cord blood: skewing toward natural killer $(\mathrm{NK})$ cell-activating antibodies was demonstrated in the latter across multiple antigens. This selective transfer was linked to digalactosylated Fc-glycans of antigen-specific IgG1 antibodies that show enhanced binding to FcRn and FcyR3A on NK cells. This may suggest an evolution of the placenta to selectively transfer antibodies with the most functional potential in the neonatal immune context, boosting protection, particularly anti-viral defense, in early life (Jennewein et al., 2019).

Therefore, establishing antibody glycosylation patterns associated with clinically relevant outcomes could inform the design of the next generation of improved maternal vaccines (Lofano et al., 2018; Rice et al., 2020). Equally, immunization itself is an optimal model to interrogate glycosylation patterns, gestational imprinting as well as in vivo regulation and persistence of glycosylation mechanisms (Alter et al., 2018).

\section{Infant Gestational Age and Birthweight}

The degree of IgG transplacental transfer is dependent on duration of gestation, with minimal transfer in the first trimester, increasing exponentially as pregnancy progresses, particularly in the last 4 weeks. At term, fetal levels vary but usually exceed maternal levels by $20-30 \%$, indicating active transfer (van den Berg et al., 2011; Calvert and Jones, 2017). This change in rate of transplacental transfer may partly occur due to higher FcRn expression with advancing gestation, although this is yet to be formally demonstrated; another hypothesis is that cytotrophoblast may initially obstruct transfer, leading to improved transfer as this layer degrades (Palmeira et al., 2012; Calvert and Jones, 2017).

The reduced duration and efficiency of transfer in early pregnancy has implications for preterm infants; nevertheless this cohort has been shown to successfully benefit from maternal immunization programs (Baxter et al., 2010; Omeñaca et al., 
2018; Nieminen et al., 2019; López-Sanguos et al., 2019). Interestingly, IgG Fc glycosylation patterns of infants also depend on their gestational ages; indeed, there is a qualitative shift toward a pro-inflammatory pattern in preterm infants that might contribute to their higher risk of chronic inflammatory diseases (Twisselmann et al., 2018).

Studies have demonstrated reduced transfer of antibodies in low birthweight infants, even those born at term. This may be attributed to pathological placental changes associated with intrauterine growth retardation, such as syncytiotrophoblast knotting, villous fibrosis and avascular terminal villi, affecting the antibody-FcRn interactions (Wesumperuma et al., 1999; Okoko J. B. et al., 2001). Interestingly, Wesumperuma et al. (1999) also found that iron-deficiency anemia in Sri Lankan mothers reduced placental antibody transfer. Maternal age, parity, and type of delivery was not shown to have a significant impact (Doroudchi et al., 2003).

\section{Maternal Co-morbidities}

Maternal co-morbidities may lead to both reduced antibody production and failure of placental integrity and key tolerance mechanisms; definitive conclusions, however, are precluded by the heterogeneity of study methodologies and findings.

It is well established that serological responses to vaccines are attenuated and wane more quickly in HIV-positive populations; the impact of viral load, immunological status and anti-retroviral therapy (ART) is important albeit inconsistent between studies (Kernéis et al., 2014; Dangor et al., 2017; Falconer et al., 2018). Comparisons between HIV-infected and -uninfected women in different settings have also shown that the former group have lower baseline/pre-vaccination protective maternal antibody levels to key vaccine pathogens and impaired transplacental transfer of IgG; this includes tetanus, GBS, VZV, measles, Hib, pertussis, and pneumococcus antibodies, although it is not a universal finding (Isabel de Moraes-Pinto et al., 1996; Cumberland et al., 2007; Jones et al., 2011, 2013; Gupta et al., 2014; Dangor et al., 2015; Le Doare et al., 2015). This may be explained by a loss of epitope-specific T- and B-memory cells secondary to immunosuppressive progression of HIV-infection (Wheatley et al., 2016; Dangor et al., 2017). Findings from influenza vaccine immunogenicity studies demonstrated that HIV-infected pregnant women had decreased vaccine-induced haemagglutination-inhibition antibody titres and a reduced likelihood of seroconversion compared to HIV-uninfected women; better responses were associated with higher CD4+ T-cells but no correlation was found with viral load (Madhi et al., 2014; Nunes et al., 2015; Dangor et al., 2017). In a separate study, altered binding to Fc receptors, Fc $\gamma$ RIIa, and Fc $\gamma$ RIIIa, in addition to glycan changes in the Fc region, were proposed to contribute to impaired placental integrity (Martinez et al., 2019).

Moreover, HIV-exposed uninfected (HEU) infants have up to fourfold higher rates of morbidity and mortality from diarrhoeal and respiratory infections compared to uninfected unexposed (HUU) infants, in part explained by lower maternal production and reduced placental transfer of protective IgG (Richard, 2004; Jones et al., 2011; Dauby et al., 2016; Evans et al., 2016; Slogrove et al., 2016; Locks et al., 2017; Weinberg et al., 2018). Vaccination in pregnancy could be particularly useful in improving immunity and clinical outcomes of these vulnerable infants, provided that highly functional, long-lasting antibody can be generated and transferred by their immunized mothers (Jones et al., 2013). Optimizing ART in HIV-positive women of child-bearing age may go some way toward achieving this goal, although it is unclear if reversal of adverse effects (i.e., lower baseline antibody levels and poorer booster responses to vaccines) and/or complete immune reconstitution is possible (Burton et al., 2008; Farquhar et al., 2009; Jones et al., 2013; Dangor et al., 2017). Indeed, given that HIV-infected women in LMICs are often only initiated on ART during pregnancy, loss of antigen-specific T- and B-cell memory may already have occurred. It has to be assumed that immune-status may only be preserved by early ART initiation (Moir et al., 2010).

With several candidate RSV and GBS vaccines currently in development, an improved understanding of the effects of maternal HIV infection is needed to inform vaccination strategies in areas with a high HIV prevalence and irrespective of ART use. Maternal HIV infection has been associated with lower anti-GBS surface binding antibody concentration and antibody-mediated $\mathrm{C} 3 \mathrm{~b} / \mathrm{iC} 3 \mathrm{~b}$ deposition onto GBS bacteria of serotypes Ia, Ib, II, III, and V (Le Doare et al., 2015). Furthermore, immunogenicity of a $\mathrm{CRM}_{197}$-conjugated trivalent GBS vaccine was found to be lower in HIV-infected pregnant women compared to HIV-uninfected women, irrespective of CD4+ T-cell counts (Heyderman et al., 2016). Similarly, Patel et al. (2019b) recently showed that maternal HIV infection was associated with lower mother-to-fetus transfer of serum RSVneutralizing antibodies. Among HEU newborns, higher birth weight and an undetectable maternal antenatal viral load were significantly associated with more effective placental transfer of RSV antibodies (Patel et al., 2019b). Nevertheless, validated assays and correlates of protection are needed to understand the potential protective value of these vaccines.

Women with other congenital or acquired immunodeficiencies, such as common variable immunodeficiency, or taking immunosuppressive medications, also have impaired serological responses, reducing production and transplacental transfer of immunoglobulins from those mothers to their offspring (Palmeira et al., 2012).

Beyond immunodeficiency, previous studies have demonstrated that placental malaria impairs transplacental transfer of different antigen-specific IgG populations due to parasitic damage to the villi architecture described earlier. This has been shown in the context of tetanus, measles, Streptococcus pneumoniae, HSV-1, EBV, RSV, and VZV antibodies (Brair et al., 1994; Isabel de Moraes-Pinto et al., 1996; O’Dempsey et al., 1996; Okoko B. J. et al., 2001; Cumberland et al., 2007; Ogolla et al., 2015) although results are conflicting, potentially due to differences in the study population and laboratory assays used (Calvert and Jones, 2017). Subsequent data from malariaendemic Papua New Guinea proposed that the association previously reported between malaria and impaired RSV antibody transfer and/or reduced RSV cord titres, may have been confounded by prematurity or hypergammaglobulinemia (IgG > 1,700 mg/dL) (Atwell et al., 2016, 2019). In fact, the 
impact of high total IgG concentrations on placental IgG transfer efficiency has previously been shown (Gonçalves et al., 1999; Hartter et al., 2000; Okoko B. J. et al., 2001) in both HIVinfected and -uninfected populations (Martinez et al., 2019). The underlying mechanism is unknown but likely due to saturation of nFcRs (Englund, 2007; Fouda et al., 2018).

Chronic helminth infections during the time of vaccination are thought to impair the induction and duration of protective immune responses elicited by vaccines (Dauby et al., 2012; Gent et al., 2019) potentially contributing to attenuated vaccine responses observed in pregnant cohorts in developing countries where helminth infections are endemic (Sabin et al., 1996; Elias et al., 2005; Riner et al., 2016).

Other infectious or inflammatory conditions, including hypertension, hyperglycaemia and placental pathologies (e.g., preeclampsia), may alter IgG production, damage placental villi, decrease FcRn expression and/or compromise transplacental transfer rate (França et al., 2012; Predoi et al., 2015; de Souza et al., 2016; Fouda et al., 2018). Of note, however, these conditions are also associated with prematurity and intrauterine growth retardation (Palmeira et al., 2012). There are no specific studies relating to maternal vaccination in these risk groups.

\section{Factors Affecting Maternal Antibody Transfer in Breast Milk}

Similar factors may contribute to maternal antibody transfer in breast milk, although there is paucity of data. One example is the impact of vaccination timing and gestational age; significantly more sIgA (and IgG) was measured in the colostrum and mature breast milk of women who delivered preterm, waning more gradually than in term women (Araújo et al., 2005; Ballabio et al., 2007). This may be an immunological adaptive response boosting protective immunity to vulnerable preterm infants (Gregory and Walker, 2013). Survival and stability of milk antibodies is also higher with prematurity (Demers-Mathieu et al., 2018).

Equally, IgA Fc region characteristics may determine IgA passive transfer or effector function in breast milk (Goonatilleke et al., 2019; Langel et al., 2020; Steffen et al., 2020). Of note, the glycosylation pattern of $\operatorname{IgA}$ antibodies is more complex, extensive and diverse; IgA2 is found at a higher percentage in mucosal secretions and has a great number of conserved $\mathrm{N}$-glycans compared to $\operatorname{IgA} 1$, which dominates in serum (Mattu et al., 1998). N-glycan profiles may also be influenced by delivery mode (Goonatilleke et al., 2019). Further defining the molecular determinants of antibodies in breast milk, and whether they complement placentally derived antibodies, may enable streamlining of breast milk immunity through maternal vaccination and other postnatal strategies (Kollmann et al., 2020).

\section{Beyond Maternal Antibody}

To date, the goal of immunization in pregnancy has primarily been to induce robust maternal antibody responses. Nevertheless, robust vaccine-elicited maternal T-cell responses may also be required to ensure complete protection, particularly against transplacental pathogen transmission and subsequent congenital disease. In the context of CMV, for example, T-cell responses may contribute to eliminating virus-infected cells and supporting $\mathrm{B}$-cell responses, with $\mathrm{CMV}$-specific $\mathrm{CD} 4+\mathrm{T}$-cell frequency and/or proliferation playing a critically important role in preventing transmission during pregnancy (Revello et al., 2006; Lilleri et al., 2007; Fornara et al., 2016). This may need to be harnessed if an effective maternal vaccine is to be developed.

In addition, maternal cells are increasingly thought to migrate transplacentally to offspring at low frequencies (Kinder et al., 2015). Further pathogen-specific immunity may, therefore, be conferred to the newborn, enhancing protection already delivered by maternal antibody (Albrecht and Arck, 2020; Kollmann et al., 2020). This is based on the principle that bidirectional transfer can occur during pregnancy, with seeding of genetically foreign maternal and fetal cells, known as 'microchimeric cells.' The biological function and molecular phenotypes of these rare fetal (FMC) and maternal (MMC) microchimeric cells is poorly understood. It is hypothesized that they may help establish immunological tolerance to an expanded repertoire of familially-relevant 'extended-self' antigens, as well as promote the success of future pregnancies by conferring cross-generational reproductive benefits. The underlying principles, immunological implications, potential advantages and harmful consequences of microchimerism have been reviewed extensively elsewhere (Kinder et al., 2015, 2017a; Jennewein et al., 2017).

The MMCs express non-inherited maternal antigens and can persist in the offspring long-term, detectable even up to 62 years postnatally. A considerable proportion belong to the immune compartment, particularly T-cells or tissue-resident memory cells (Albrecht and Arck, 2020); it is estimated that up to 1 in 5,000 peripheral blood mononuclear cells may be of maternal origin (Kinder et al., 2017a). In a previous case of a human infant with severe combined immunodeficiency, activated CD8 ${ }^{+}$T-cells and IFN- $\gamma$-secretion were detected in response to EBV infection; these cells displayed a maternal genotype (Touzot et al., 2012). Furthermore, using a mouse model, a recent study established that non-inherited maternal antigen-specific regulatory $\mathrm{T}$-cells are acquired in early life and persist in the genital tract of female offspring, thereby supporting a role for MMCs in the immunological development of infants and cross-generational reproductive fitness (Kinder et al., 2015).

Microchimerism is less well-established in the context of breast milk; animal experiments and limited human-based observations suggest that maternal immune cells can be detected in breast milk and may traffic to infant tissues through gut mucosae (Palmeira and Carneiro-Sampaio, 2016; Kinder et al., 2017b; Molès et al., 2017). This phenomenon most likely occurs during the early stages of lactation, primarily colostrum, when breast milk cell abundance and infant gut permeability are highest. These MMCs may include stem cells, progenitor cells and/or mature immune cells (such as IgG-producing memory B-cells and memory T-cells), although this remains poorly understood (Kinder et al., 2017b; Marchant et al., 2017). Interestingly, a recent murine study demonstrated that, under the same activation conditions, 
maternally-derived CD8+ T-cells in breast milk are superior in generating potent mediators compared to the infant's endogenous cellular compartment. This may be a compensatory mechanism for the infant's unique adaptive immune system during the vulnerable postnatal phase (Cabinian et al., 2016). Molès et al. (2017) hypothesize, therefore, that the transfer of viable maternal immune and stem cells from breast milk to an infant may contribute to optimizing neonatal and infant immune system maturation, cross-generational reproductive fitness, tissue repair and immune tolerance, thereby complementing pregnancy-associated MMCs (Molès et al., 2017). However, this hypothesis has been challenged and the exact mechanisms are yet to be fully elucidated, particularly in the context of vaccine-induced maternal leukocyte transfer (Kinder et al., 2017b).

\section{SO, IS THERE A RIGHT TIME TO VACCINATE?}

The optimal timing of vaccination in pregnancy remains debated and the kinetics will have to be considered when strategically deploying maternal vaccination to maximize impact in the future (Calvert and Jones, 2017). A recent review of prevalence and decay of maternal antibodies from different pneumococcal and meningococcal vaccine trials demonstrated differences between serotypes, serogroups, and countries (Voysey et al., 2017). Moreover, many countries advise to immunize against pertussis at every pregnancy, since antibodies rapidly wane after an adult booster dose and decline in the infant after birth, mostly within 2 months (Halperin et al., 2011; Healy et al., 2013).

Vaccination in the first trimester is usually avoided as this trimester is associated with higher risk of pregnancy loss and the time of major fetal organogenesis. Approaches that favor third trimester immunization point to the relatively short halflife of vaccine-induced antibody, efficiency of placental transfer as gestation advances and the need to match the highest antibody levels with the peak of transplacental IgG transport (Healy et al., 2013; Naidu et al., 2016; Winter et al., 2017). Vaccinating earlier in pregnancy, however, is likely to provide better protection for preterm infants. Eberhardt et al. (2016) proposed that maternal pertussis immunization in the second trimester maximized antibody transfer and expected infant seropositivity against pertussis, potentially because antibody can accumulate over a longer time period following earlier vaccination. Furthermore, timing may impact antibody avidity in cord blood, with a recent study demonstrating that newborns of women receiving pertussis vaccinations between 27 and $30+6$ weeks gestation had a higher relative avidity index than those of mothers vaccinated later (Abu Raya et al., 2015). Nevertheless, a remainder of studies have shown no significant relationship between timing of maternal vaccination and subsequent antibody levels in cord/infant blood or proportions achieving protective thresholds for most antigens (Ladhani et al., 2015; Vilajeliu et al., 2015), hence these kinetics might differ between vaccines and the respective antibody levels they can induce.

\section{ONCE TRANSFERRED, WHAT DO WE KNOW ABOUT THE EFFECT OF MATERNAL ANTIBODY ON THE NEWBORN IMMUNE SYSTEM?}

\section{Systemic Infant Humoral Immunity}

One of the main controversies in the field of maternal immunization is whether high maternal vaccine-induced antibody titres interfere with or 'blunt' the infant's endogenous antibody response following primary immunization and, therefore, potentially threaten effective disease protection. Blunting has been demonstrated previously in the context of pertussis, influenza, tetanus, diphtheria, measles, and mumps immunity, hence it is an important consideration for future maternal vaccine development and implementation (Englund, 2007; Jones et al., 2010, 2014; Ladhani et al., 2015; Maertens et al., 2017; Zimmerman et al., 2019; Orije et al., 2020).

Several mechanisms have been proposed to explain an inhibitory effect of maternal antibody on infant B-cell responses: (1) antigen neutralization of live replicating viral vaccines (2) epitope masking preventing antigen binding by infant B-cells, thereby limiting their priming, the most popular theory (3) inhibition of infant B-cell activation by FcyRIIBreceptor-mediated signaling, and (4) removal of maternal antibody-vaccine antigen immune complexes by Fc-dependent phagocytosis (Siegrist, 2003; Kim et al., 2011; Niewiesk, 2014; Edwards, 2015).

Although a blunting response has been demonstrated, this data is generated from immunogenicity studies and, to date, there is no evidence of relevance to clinical outcomes (disease incidence or severity) (Kandeil et al., 2020); however, this is difficult to ascertain, particularly with vaccines that have no definitive correlate of protection (CoP). Despite the association between low anti-PT IgG titres and high susceptibility to pertussis disease, a protective antibody threshold is yet to be established (Storsaeter et al., 2003). Nevertheless, surveillance data collected in settings where maternal pertussis immunization programs have been implemented show a highly successful reduction in disease morbidity and mortality in early life (Amirthalingam et al., 2014, 2016; Switzer et al., 2019; Forsyth et al., 2020; Jarvis et al., 2020).

Furthermore, the blunting effect noted has not been comprehensively defined, with a gap in our understanding of the impact of maternal antibody on qualitative or functional infant humoral immunity. Pre-existing antibodies have been shown to induce higher affinity humoral responses, possibly explained by competitive binding in the germinal center (GC) and/or a boost in uptake and antigen presentation, mediated by immune complexes in a Fc glycosylation-dependent manner (Zhang et al., 2013; Lofano et al., 2018; Garg et al., 2019; Langel et al., 2020). Most recently, a randomized control trial in Thailand (NCT02408926) studied term infants who were immunized with either acellular $(\mathrm{aP})$ - or whole cell $(\mathrm{wP})$ pertussis vaccines in infancy; results showed that infants born to women vaccinated in pregnancy had reduced pertussis-specific titres. Despite this, antibody functionality (as determined by B. pertussis growth 
inhibition assay) was overall better in wP-vaccinated infant sera, and after maternal immunization. These data suggest that maternal antibodies may boost the production of antibodies with distinct biophysical features to achieve effective pathogen control in the infant (Wanlapakorn et al., 2019).

Finally, many have argued that blunting is short-lived and reversible, especially as maternal antibodies decline over time, and does not remain significant following booster vaccination (Munoz et al., 2014; Le Doare et al., 2015; Hoang et al., 2016). Longitudinal follow-up studies, therefore, are required to arrive at stronger conclusions on the clinical implications of blunting, if any, potentially also in the context of different infant immunization schedules and environmental exposures. Such studies are hard to do in the absence of meticulous longterm follow-up of infants born to vaccinated mothers, at the population level.

\section{Systemic Infant Cellular Immunity}

To date, vaccine-induced CoPs are predominantly defined by the development of serum antibody responses using quantitative assays, with less focus on cell-mediated immunity (CMI), despite the significant induction of cellular responses post-vaccination by some vaccines, such as pertussis, and the important role CMI plays in disease protection (Ausiello et al., 1999; da Silva Antunes et al., 2018; Poland et al., 2018; Wilk and Mills, 2018). This extensive knowledge gap is likely due to the practical and biological difficulties of accurately and reliably measuring CMI. Assays are costly, challenging, labor-intensive, often requiring large amounts of blood and, above all, poorly standardized, limiting comparisons between different studies (Wilcox and Jones, 2018).

A lowered antibody titre, caused by the blunting effect, does not necessarily imply reduced protection; a recent comprehensive review concluded that in the majority of both human and animal studies, priming of CMI after infant vaccination occurred even in the presence of high maternal antibody titres, with minimal or no blunting effect on cellular responses reported (Orije et al., 2020). Furthermore, in two studies, maternal antibodies were even found to stimulate a more robust CMI response, highlighting a potential secondary beneficial effect of maternal immunization (Bertley et al., 2004; Rowe et al., 2005).

In contrast to other blunting theories, a recent study by Vono et al. (2019) showed that maternal antibodies do not prevent neonatal B-cell activation but exert their influence by limiting the expansion of T-follicular helper cells, thereby shaping GC output, i.e., B-cell differentiation into effective plasma cells and/or memory cells, and the antigenspecific B-cell repertoire (Vono et al., 2019). Interestingly, at low or intermediate titres, maternal antibodies did not prevent the induction of memory-cells, suggesting a gradient effect on infant immune responses (Vono et al., 2019; Langel et al., 2020).

\section{In utero Sensitisation and Priming}

There is now a growing body of evidence that the fetal immune system may be shaped by vaccination through more than just the passive immunity provided via IgG transfer. One potential mechanism, discussed previously, is maternal microchimerism, which is due to transplacental bi-directional migration of cells and may play a role in neonatal immune modulation (Kinder et al., 2017a). Furthermore, as demonstrated already in the context of infectious disease antigens (Bisseye et al., 2009; Malhotra et al., 2009; Dauby et al., 2012; Zhivaki and Lo-Man, 2017; Odorizzi et al., 2018) the fetus may also be sensitized in utero, both qualitatively and quantitively, to vaccine antigens to which the mother has encountered during pregnancy, either as free antigens or antigen-antibody complexes (or, potentially, antigen-loaded vesicles, Tong and Chamley, 2015). This exposure during fetal development has previously been shown to imprint immunological tolerance to non-inherited 'foreign' maternal antigens, persisting beyond early infancy into adulthood (Kinder et al., 2015, 2017a; Jennewein et al., 2017).

Previous studies of maternal immunization have identified antigen-specific IgM in cord blood, assumed to be secondary to activation of fetal B-cells, given that minimal IgM crosses the placenta; this has been demonstrated following influenza and tetanus vaccination, although there is little data following pertussis immunization (Gill et al., 1983). Rastogi et al. (2007) detected antigen-specific T-cells (more directly, using $\mathrm{MHC}$ Class I tetramers) in the cord blood of infants born to influenza-vaccinated compared to non-vaccinated mothers; their phenotype was $\mathrm{CD} 45 \mathrm{RO}+$, indicating an effector memory $\mathrm{T}$ cell response, usually not demonstrated in cord blood, and therefore proposed to be secondary to vaccine-induced in utero priming (Rastogi et al., 2007). Such memory T-cells display various effector functions, including Th1, Th2, or Th17 profiles (Zhivaki and Lo-Man, 2017). Other studies, however, have challenged that these proposed antigen-specific fetal Tcells are conventionally primed memory T-helper cells; instead, they may represent 'recent thymic migrants', a common cell population in the neonatal cohort and a transitional subtype between thymocytes and adult T-cells (Wilcox and Jones, 2018). More research in this area is required and a systems approach might be needed to better understand the complexities and interdependencies.

The potential clinical relevance of these findings also remains unclear. Vaccine-induced in utero generation of $\mathrm{T}$ cell memory could benefit the neonate by shaping immune ontogeny and conferring pathogen-specific protection, beyond antibody-mediated passive immunity (or Th2skewed responses). Moreover, it may be relevant in cases where the pediatric primary immunization course is too late to prevent severe disease, for example, with GBS or RSV infections in early life (Zhivaki and Lo-Man, 2017). The possible impact on responses to childhood vaccines must also be explored.

\section{Heterologous (Non-specific) Effects}

Another recent concept with relevance to the impact of vaccination in pregnancy on the mother, fetus or newborn is the notion of heterologous or 'non-specific effects' (NSE) of vaccines, including heterologous lymphocyte effects and 
induction of innate immune memory ('trained immunity'). The latter is thought to be mediated by epigenetic and metabolic reprogramming which elicits long-term functional upregulation of innate immune cells (Netea and van der Meer, 2017; de Bree et al., 2018). NSE are hypothesized to explain findings by some studies that certain vaccines have a broader impact on health outcomes than previously appreciated; protection may be conferred against unrelated pathogens, beyond those specifically targeted by the original vaccine design (Aaby et al., 2010; Saadatian-Elahi et al., 2016; Pollard et al., 2017; de Bree et al., 2018; Uthayakumar et al., 2018). This is currently an under-explored area of research within the mother/infant dyad, although one recent study did show that maternal MF59-adjuvanted influenza immunization was associated with an altered cytokine profile in the nasal mucosa of 4-week-old infants subsequently, when compared to those born to unvaccinated mothers (Bischoff et al., 2015). This may be important when modeling the impact of programs that harness a dual maternal and infant vaccination strategy (Munoz et al., 2018).

\section{Infant Mucosal Immunity}

In addition to preventing disease, maternal immunization may be a strategy to protect young infants from early bacterial carriage at the mucosa, via either breast milk- or transplacentally derived antibody (Chaithongwongwatthana et al., 2015). This is being explored particularly in the context of maternal pneumococcal, GBS and pertussis vaccines, whereby colonization is a prerequisite to invasive disease, although results are inconclusive and potentially confounded by maternal carriage status at birth (Munoz et al., 2001; Le Doare et al., 2017; Ojal et al., 2017). A vaccine-induced CoP may, therefore, need to be defined as a composite measure in some cases, addressing impact on carriage, infection and disease.

Similarly to transplacental antibody, we must consider whether interference from vaccine-derived antibodies in breast milk may impede immunogenicity of mucosal vaccines; it has been speculated that this may contribute to the poor performance of live oral rotavirus immunizations given to infants in LMICs, where breastfeeding rates are high (Jiang et al., 2014; Parker et al., 2018). A recent systematic review evaluating the role of maternal immunity in rotavirus vaccine immunogenicity concluded that higher levels of transplacental rotavirus-specific IgG antibody and, to a smaller extent, breast milk rotavirus-specific IgA contribute to reduced or failed rotavirus vaccine seroconversion in infants; however, clinical trials withholding breastfeeding at the time of vaccination had no significant effect on vaccine responses (Rongsen-Chandola et al., 2014; Mwila et al., 2017). Nevertheless, antibodies or other immune factors may persist in the infant's gastrointestinal tract for longer periods than the time spent on withholding feeds. Maternal IgG/IgA antibodies have also been shown to dampen mucosal cellular responses against commensal bacteria in mice (Koch et al., 2016). Lack of a definitive CoP, however, similarly applies to breast milk studies. Even with vaccines that have a known CoP, it is unclear whether this can be extrapolated to sIgA titres in breast milk (Plotkin, 2010; Maertens et al., 2014).

\section{THE BIGGER PICTURE: WHAT ELSE INFLUENCES THE MOTHER/INFANT DYAD OF INTERACTIONS?}

We have already discussed factors that may affect transfer of maternal antibody to infants, but adequate production of antibody in the first place is a crucial determinant of subsequent infant antibody titres. Further maternal, neonatal and environmental factors also shape the early immunological milieu and, therefore, the success of maternal immunization (Kollmann et al., 2017). A detailed discussion of all key factors impacting vaccine responses in general is beyond the scope of this article and has been extensively reviewed elsewhere (Zimmermann and Curtis, 2019).

\section{Host Factors}

\section{Intrinsic}

It is well established that age and sex affect vaccine-induced immunity, particularly quantitative antibody responses, relevant to both the pregnant woman and her developing infant (Baxter et al., 2010; Omeñaca et al., 2018; Chiappini et al., 2019; LópezSanguos et al., 2019).

Specifically, females display enhanced immune reactogenicity, with higher antibody responses and adverse events, than males (Fischinger et al., 2019). Furthermore, immunogenetic studies have suggested that host genetic polymorphisms modulate heterogeneity in vaccine responses in the context of numerous immunizations, for example, against measles, hepatitis $B$, influenza A, BCG, HiB, and certain Neisseria meningitidis serotypes. This includes variants in the genes regulating both innate and adaptive compartments, encoding Toll-like receptors, HLA molecules, cytokines, and cytokine receptors. However, very few data are available from studies conducted in infants (Newport, 2015; Linnik and Egli, 2016).

\section{Nutritional Status}

The effect of nutritional status and nutritional supplements is contentious. Many studies in adults show that an elevated body mass index (BMI) is inversely correlated with longterm vaccine-induced antibody responses (Sheridan et al., 2012). By contrast, adequate maternal nourishment, particularly micronutrient intake, is important to achieve optimal vaccine responses (Wu et al., 2019); malnutrition may be exacerbated in pregnancy when nutritional demand is highest. Exposure to a nutritionally deficient environment during fetal life and early infancy may further adversely alter the ontogeny of the neonatal immune system, impacting early growth and development, including the infant's ability to mount optimal immune responses to vaccination. A recent randomized trial in rural Gambia, the Early Nutrition and Immune Development (ENID) study, demonstrated that maternal supplementation with multiple micronutrients combined with protein-energy during pregnancy enhanced antibody responses to routine DTP vaccination in early infancy, although there were key methodological limitations (Okala et al., 2019). The mechanisms underlying these associations warrant further investigation. EMPHASIS, a study 
based in India and sub-Saharan Africa, aimed to characterize epigenetic features linking pre-conceptional nutrition and subsequent health-related outcomes in children, although specific vaccine responses are yet to be elucidated (Chandak et al., 2017). Investigations into the immunological benefits of vitamins, such as vitamins $\mathrm{A}, \mathrm{B}$, or $\mathrm{D}$, report conflicting, inconclusive results (Sadarangani et al., 2015; Zimmermann and Curtis, 2019).

\section{Environmental Factors Geographical Setting}

Geographical setting, both defined by development status or urban/rural location, is known to play a role in immune responses at all ages and might also affect responses to vaccines in pregnancy (Zimmermann and Curtis, 2019). Equally, season and climate are important factors when considering disease burden and, therefore, practicalities of implementing vaccination programs during pregnancy, particularly with respiratory pathogens RSV and influenza (Moore et al., 2006).

\section{Microbiome}

Data is increasingly showing a mutualistic relationship between the intestinal microbiota and vaccine responses (Ferreira et al., 2010; Rogier et al., 2015; Gensollen et al., 2016; Nguyen et al., 2016; Lynn and Pulendran, 2018; Zimmermann and Curtis, 2018). Higher relative abundance of Actinobacteria and Firmicutes was consistently correlated with both higher antibody and cellular responses to several vaccines, including BCG, Hepatitis B, IPV, OPV, and tetanus immunizations; an inverse correlation was found for Proteobacteria and Bacteroidetes (Zimmermann and Curtis, 2018; Huda et al., 2019). There has been less focus, however, on the impact of the respiratory microbiome on vaccine responses (Mika et al., 2015, 2017; Tarabichi et al., 2015; Zimmermann and Curtis, 2018; Lee K. H. et al., 2019). One important recent study showed a positive association between nasopharyngeal colonization with Bacteroides ovatus, Lactobacillus helveticus, Prevotella melaninogenica, Streptococcus infantis, and Veillonella dispar and influenza virus-specific $\mathrm{H} 1$ and $\mathrm{H} 3$ IgA levels in nasal washings after vaccination with live-attenuated influenza vaccine (Salk et al., 2016). These findings are relevant when optimizing vaccine responses during pregnancy as well as assessing natural and vaccine-induced immune development of the infant. The underlying immunological mechanisms, however, have yet to be fully elucidated; changes in the level of microbially-derived metabolites may activate the innate immune compartment, thereby modulating development of T-and B-cells (Janoff et al., 2012; Lynn and Pulendran, 2018). Breast milk components, including the diverse array of microbiota, may further shape the neonatal immunological milieu, potentially mediated through human milk oligosaccharides/glycoconjugates, milk-derived sIgA/IgG and cytokines (Geuking et al., 2012; Rogier et al., 2015; Toscano et al., 2017; Kirmiz et al., 2018; Le Doare et al., 2018).

Although postnatal colonization plays a key role in setting the immune phenotype of the offspring, the process begins in early gestation. Using a model of reversible colonization of germ-free mice during pregnancy, signals derived from maternal microbiota were shown to influence early infant immune development and function, for example by maturing fetal/neonatal intestinal innate immune cells and altering intestinal gene expression profiles (De Agüero et al., 2016). In addition, metabolites that originate directly from the maternal diet, often modulated by the microbiota, can be transferred to the offspring and may potentially further shape its immunity (Macpherson et al., 2017). Maternal antibodies are critical in amplifying this transfer, both across the placenta in utero and during lactation, by binding and retaining bacterial products and efficiently delivering them to offspring (GanalVonarburg et al., 2017). Furthermore, Koch et al. (2016) showed that mice lacking maternal antibodies display dysregulated mucosal responses.

At present, this complex interrelationship between maternal antibody, microbiome signaling, dietary metabolites and neonatal immunity is poorly understood in humans; notably, there are no current studies relating it to different maternal vaccines and/or subsequent infant vaccine responses.

\section{Vaccine Factors}

Vaccine antigen content, dosage, adjuvant composition and route of administration will affect the quality and magnitude of immune responses both in the mother and, subsequently, her infant (Zimmermann and Curtis, 2019). In particular, modifying these factors may alter key antibody properties, related to both structure and function (Alter et al., 2018). Novel adjuvants are often added to subunit vaccines to enhance their immunogenicity, both qualitatively and quantitatively; in the context of maternal immunization, they may optimize magnitude and transplacental transfer of antigen-specific antibodies to the fetus (Francica et al., 2017). However, their potential to induce pro-inflammatory reactions and, hence, any risk of adverse reproductive, teratogenic or fetal developmental effects must first be rigorously interrogated (Herberts et al., 2010; WHO: Global Advisory Committee on Vaccine Safety, 2014).

The safety of alum-adjuvanted vaccines in pregnancy has been well established (e.g., tetanus and pertussis) and increasing evidence is emerging on oil-in-water adjuvants, such as MF59, which has shown to improve both epitope breadth and binding affinity of antibody responses if used in hemagglutinin -based influenza vaccines (Tsai et al., 2010; Rubinstein et al., 2013). Another promising example is a next-generation polysaccharide-based adjuvant developed from microcrystalline particles of delta inulin $\left(\operatorname{Advax}^{\mathrm{TM}}\right)$, so far shown to be safe and effective in seasonal/pandemic influenza vaccines in non-pregnant human adults, as well as in pregnant animal models (Honda-Okubo et al., 2014).

Induction of durable vaccine-specific antibodies with a distinct glycosylation pattern or from a particular subclass may be an effective strategy to optimize immunogenicity (Saunders, 2019). Modifying vaccine-type, dosing (single vs. multiple), delivery route and adjuvant formulation (to stimulate different Toll-like receptors) can selectively modify the Fc domain and induce glycan combinations which confer desired antibody effector functions (Selman et al., 2012; Mahan et al., 2014, 2016; Francica et al., 2017; Lofano et al., 2018). For example, 


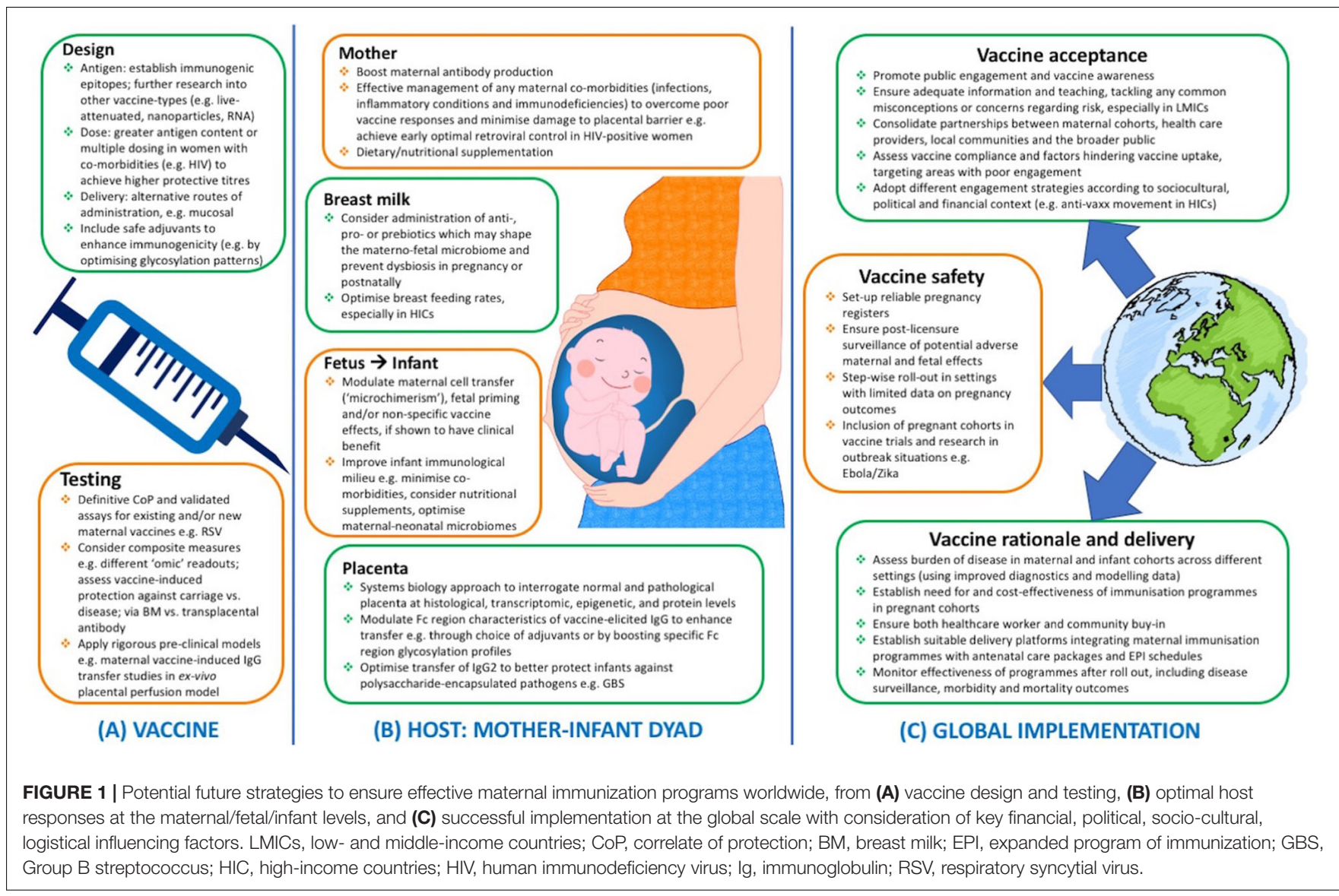

removing the glycans from IgG2b has previously eliminated its immunosuppressive activity both in vitro and in vivo (Langel et al., 2020).

The antigen composition of the vaccine is of course also key, particularly the choice of immunogenic epitopes. Live-attenuated vaccines are generally excluded from use in pregnancy due to concerns over potential reversion to virulence and subsequent fetal complications, or the risk of adverse events in immunocompromised pregnant women. Substantial literature, however, has reported no concerning effects in the fetus following monovalent rubella, combined measles-mumpsrubella, yellow fever and oral poliovirus vaccines (WHO: Global Advisory Committee on Vaccine Safety, 2014; LarisGonzález et al., 2020). Nevertheless, wider conclusive evidence on safety issues is needed to inform future recommendations, as this may be an important strategy particularly with less immunogenic vaccines.

Moreover, many novel types of influenza vaccines are under development, including those that incorporate alternative proteins derived from the nucleus or M2 channel, as well as potential 'universal' DNA and RNA vaccines (Krammer et al., 2018; Lee et al., 2018). In the context of RSV, a recent phase 2 study of a novel RSV fusion (F) protein nanoparticle vaccine given to a large cohort of third-trimester pregnant women showed promising results, even if the primary endpoint was not met (Muňoz et al., 2019).
Increased antigen load or recurrent dosing may also be important in certain cohorts, such as immunodeficient women who cannot mount sufficiently high antibody responses to reach the protective threshold with routine doses.

Finally, future vaccine development should consider the impact of different delivery systems or immunization routes, including mucosal strategies, particularly if protection against colonization is established as an important endpoint.

Above all, pregnant women have been traditionally excluded from many vaccine trials, which has precluded sufficient good quality data on long-term maternal/fetal safety and vaccine-induced efficacy within this cohort. Fortunately, recent initiatives and multi-stakeholder involvement are beginning to turn the tide.

\section{APPROACHES TO CLOSE OUR GAPS IN KNOWLEDGE}

\section{Methodology}

The advent of systems vaccinology has enabled us to generate multifaceted datasets using high- throughput technologies and integrate them with sophisticated computational analysis, providing detailed insights into the effects of maternal immunization, associations between materno-fetal immunological parameters, interactions at the placental barrier 


\begin{abstract}
BOX 1 | Gaps in knowledge and future avenues of research in pregnant women.

- Changes in placental structure, development and function throughout gestation, including materno-fetal regulatory mechanisms.

- Factors that determine placental integrity, successful maternal IgG-FcRn interactions, and subsequent efficacy of (bi-directional) transplacental transport.

- Impact of maternal antibody avidity on placental transfer and the impact of timing on avidity.

- Quantitative and qualitative changes in Fc glycosylation throughout pregnancy and across different antigen-specific populations, as well as the effect of pregnancy, disease and specific vaccine factors on glycosylation patterns.

- Biological and clinical implications of distinct glycosylation profiles, including potential association with Fc-mediated maternal antibody interference.

- Detailed mechanisms underlying breast milk antibody transfer and key regulating factors.

- Effects of vaccination during pregnancy on the composition of breast milk, particularly the presence of pathogen-specific slgA antibodies.

- How vaccine design, delivery, dosing and timing may determine efficacy of antibody transfer, in the context of different types of vaccines.

- Robust experimental models to interrogate the materno-fetal interface, specifically utilizing new technologies and imaging techniques.

- Definitive (potentially composite) correlates of vaccine-induced protection for key maternal vaccines.
\end{abstract}

and a full characterization of breast milk analytes (Nakaya and Pulendran, 2015; Poland et al., 2018; Lee A. H. et al., 2019). To date, however, our lack of standardized tools to quantify antigen-specific T-cells has hampered our ability to confirm the evidence of in utero sensitisation and priming of the fetal immune system following exposure to maternal vaccine antigens, and to fully characterize the impact of maternal antibody on subsequent vaccine-specific cellular responses in infants.

Novel approaches include the study of high-dimensional cell-subset immunophenotyping through CyTOF (Porpiglia et al., 2017; Lingblom et al., 2018; Reeves et al., 2018) and vaccine-induced changes at the metabolic ( $\mathrm{Li}$ et al., 2017) proteomic (Galassie and Link, 2015) genetic and transcriptional (Stubbington et al., 2017) levels. This knowledge is largely being harnessed to establish signatures predictive of vaccine immunogenicity (Pezeshki et al., 2019), although early inflammatory transcriptomic profiling has recently been explored in the context of vaccine safety (Tregoning et al., 2020). Systems serology has also been used to define $\mathrm{Fc}$ features associated with antibody transfer and effector function, as discussed previously (Chung and Alter, 2017; Jennewein et al., 2019) including a detailed characterization of adjuvant effects on antibody quality (Francica et al., 2017). This could be extended to breast milk antibodies and interactions, given the lack of a validated standardized assay for sIgA.

Conversely, a systems vaccinology approach can help to understand the effect of pregnancy itself on vaccination, including the specific acute inflammatory pathways induced and markers of immunogenicity/safety. Using Boostrix vaccine (combined diphtheria, tetanus, multivalent acellular pertussis), Tregoning et al. (2020) demonstrated that pregnancy might have minimal impact on initial vaccine-induced responses; they observed characteristic patterns of gene expression,
BOX 2 | Gaps in knowledge and future avenues of research in infants.

- Application of novel systems biology tools to investigate placental, maternal, fetal, and neonatal immune compartments.

- Standardized qualitative and quantitative assays to fully characterize the short-, intermediate- and long-term effects of maternal immunization on fetal and neonatal immunity.

- Targeted studies on the maternal, neonatal (both genetic and acquired) and environmental co-factors shaping early neonatal quantitative and qualitative immune responses.

- Mechanisms explaining blunting and its potential impact on functional responses.

- Mechanisms underlying potential maternal vaccine-induced microchimerism and in utero priming, plus the impact on subsequent infant cell-mediated responses to primary vaccines, including heterologous effects.

- Interactions between $\lg G$ with other Fc receptors, particularly on fetal or neonatal innate cells.

- The role of vaccine-induced mucosal cellular immunity and its interaction with mucosal humoral responses and/or microbiota communities.

- Impact of breast milk immune factors induced by maternal immunization on infant immune responses.

- Biological and clinical relevance of immune phenomena induced by maternal vaccination in the context of infant infection and immunity.

including upregulation in interferon response and innate immunity gene modules that were independent of pregnancy, irrespective of baseline differences and similar in both women and mice. Given this, they propose that studies in non-pregnant women can provide information about maternal vaccine immunogenicity and potentially safety; using murine models may also be promising in this context (Tregoning et al., 2020).

Therefore, it is hoped that newer 'omics' assays may elucidate key mechanisms controlling vaccine immunity, particularly functional responses, define molecular signatures, identify novel $\mathrm{CoP}$ and predict clinical end-points, including safety. It is time to direct these tools to the maternal/infant dyad during clinical trials.

\section{Experimental Models}

These methods must be applied within a convincing model of the materno-fetal interface. Paired maternal-cord samples, specifically the ratio of cord:maternal antibody concentration, are often used as a surrogate for placental transfer, although this fails to provide mechanistic insights.

\section{Animal Models}

Animal models have provided 'biologically complete' insights into the possible mechanisms of FcRn-mediated IgG transfer, overcoming ethical and practical limitations of human studies. Nevertheless, the morphological, developmental, physiological and immunological characteristics of the placenta often vary between humans and animals, including the expression of FcRn and mechanisms of IgG transport (Carter, 2007; Grigsby, 2016).

Similarly, animal models of breast milk production/transfer are limited; differing from humans, IgG is the primary immunoglobulin class in milk throughout many animal species (rodents, bovines, cats, and ferrets), predominantly transported across the duodeno-jejunal epithelium into the neonatal circulation (similar FcR-mediated mechanism to 
human transplacental transfer) (Van De Perre, 2003). The protective effect of breast milk may be proven by performing foster feeding studies, whereby offspring of immunized mothers are nursed by non-immunized mothers and vice-versa, clearly not feasible in human cohorts (Maertens et al., 2014; Grigsby, 2016).

\section{Human in vitro Models}

Freshly isolated primary term cytotrophoblasts can be cultured, differentiating into multinucleated syncytiotrophoblast cells, although there may be ethical, biological and practical constraints (Depoix et al., 2013). Alternatively, immortalized or choriocarcinoma-derived cell lines are used in directional transport and metabolic studies (Orendi et al., 2011); when combined with fluorescence microscopy of FcRn-green fluorescent protein-transfected live human endothelial cells, analysis of the intracellular trafficking of $\operatorname{IgG}$ is facilitated in real-time (Ober et al., 2004; Turco and Moffett, 2019). Another strategy is the placental explant model, prepared from the villous placenta (usually from early terminations) and adhering to a plastic or defined matrix. This can be used both ex-vivo or invitro and performed at any stage of gestation, unlike trophoblast cells or placental perfusion models, enabling interrogation of early placental function (Miller et al., 2005; Viall et al., 2013). These models have recently helped to demonstrate bi-directional extracellular vesicle-mediated transfer of proteins, lipids and nucleic acids (Tong and Chamley, 2015); exosomes from activated immune cells were shown to signal to the placental unit, contributing to materno-fetal communication, in addition to modulating placental- and possibly fetal- immunity (Holder et al., 2016; Aengenheister et al., 2018). This warrants further investigation in the context of maternal disease and vaccine antigens/immunity. Moreover, to date, application of these models to antibody investigations has been limited.

\section{Human ex vivo Models}

The gold standard for assessing placental transfer is the placental perfusion model, although it is complex and technically challenging, requiring very rapid access to fresh placenta samples (Conings et al., 2017). A placental cotyledon is cannulated and dually perfused to replicate the independent fetal and maternal circuits. This technique is simplified, primarily modeling the term placenta without adjusting for potential maternal/fetal physiological variables; nevertheless it has enhanced our understanding of human placental transfer of key substances, including immune complexes in the context of maternal disease (May et al., 2009; Hutson et al., 2011; Wilcox et al., 2017). Further studies following maternal immunization would be timely.

Recently, there have been collaborative efforts (e.g., The Human Placenta Project) to optimize our existing models and/or apply novel technologies to more accurately recapitulate the diverse cell types and complex interactions at the maternofetal interface. Key examples include co-cultures cultivating both trophoblastic and endothelial cells on a membrane; threedimensional trophoblast organoids; computational modeling of tissue dynamics and blood flow; and bio-engineered tissue constructs (Guttmacher et al., 2014; Huckle, 2017; Aengenheister et al., 2018; Turco et al., 2018).

\section{BEYOND BIOLOGY}

With the considerable international interest in vaccination in pregnancy by academic researchers, industry and community stakeholders alike, it has become apparent that in addition to the multitude of biological challenges summarized above, considerable implementation challenges also need to be addressed (Bonhoeffer et al., 2016; Munoz, 2018; Munoz et al., 2018). These relate to safety, equity of access, acceptability, prioritization, standardization of clinical diagnoses, use of not-yet licensed vaccines in emergency situations like Ebola or Lassa, to name but a few. There is a need for pregnancy registers to capture long-term outcomes, beyond clinical trials. How to set this up in LMICs where, ultimately, these vaccines might have the largest impact on maternal and neonatal health, but where the background rates of pregnancy and neonatal outcomes are not as reliably captured as in HICs, remains a considerable challenge. Many other reviews have comprehensively addressed these topics.

\section{JOINING FORCES TO ADDRESS BOTH BIOLOGICAL AND IMPLEMENTATION CHALLENGES}

Over the last 2 years, IMPRINT, the international IMmunising PRegnant Women and INfant NeTwork has brought together investigators and stakeholders in 50 countries across the globe to conduct research into specific biological and implementation challenges. The Pregnancy Research Ethics for Vaccines, Epidemics, and New Technologies (PREVENT) team has set out a framework for ethical consideration of inclusion of pregnant women in clinical trials of new vaccines (Prevent, 2020); more specific roadmaps for the introduction of vaccines against GBS (WHO GBS vaccine research development technical roadmap, 2020) and RSV have also been developed (PATH, 2018). The Bill and Melinda Gates Foundation (BMGF) and WHO have each committed significant resources to the subject and supported the academic community, with industry as a further key stakeholder, in driving forward the agenda to develop and implement safe and effective vaccines in pregnancy.

Figure 1 summarizes potential future strategies to optimize the success of maternal immunization programs worldwide, addressing both biological (vaccine and host-related) factors and implementation challenges.

\section{CONCLUSION}

In Boxes 1, 2 below, we have outlined key avenues of research, either targeted to the materno-fetal interface or the infant, which could enhance our understanding of the underlying immunobiology and inform design and testing of the next generation of safe and effective vaccines in pregnancy.

As we have summarized in this review, significant progress has been achieved to understand how mother and child are 
immunologically linked, thereby optimizing vaccine design to effectively and safely target this materno/fetal dyad. Much more remains to be done in this exciting area of vaccinology, which has already achieved unprecedented and laudable multistakeholder engagement.

\section{AUTHOR CONTRIBUTIONS}

BK developed the concept for the review and provided senior support. AS conducted the literature review and wrote the first draft. Both authors contributed to writing the manuscript and reviewed the final draft.

\section{FUNDING}

We acknowledge funding from UKRI/MRC/BBSRC for the Immunising Pregnant Women and Infants

\section{REFERENCES}

Aaby, P., Martins, C. L., Garly, M. L., Balé, C., Andersen, A., Rodrigues, A., et al. (2010). Non-specific effects of standard measles vaccine at 4.5 and 9 months of age on childhood mortality: randomised controlled trial. BMJ 341:c6495. doi: 10.1136/bmj.c6495

Abdiche, Y. N., Yeung, Y. A., Chaparro-Riggers, J., Barman, I., Strop, P., Chin, S. M., et al. (2015). The neonatal Fc receptor ( $F C R n)$ binds independently to both sites of the IgG homodimer with identical affinity. MAbs 7, 331-343. doi: 10.1080/19420862.2015.1008353

Abu Raya, B., Bamberger, E., Almog, M., Peri, R., Srugo, I., and Kessel, A. (2015). Immunization of pregnant women against pertussis: the effect of timing on antibody avidity. Vaccine 33, 1948-1952. doi: 10.1016/j.vaccine.2015.02.059

Abu Raya, B., Srugo, I., Kessel, A., Peterman, M., Bader, D., Peri, R., et al. (2014). The induction of breast milk pertussis specific antibodies following gestational tetanus-diphtheria-acellular pertussis vaccination. Vaccine 32, 5632-5637. doi: 10.1016/j.vaccine.2014.08.006

Aengenheister, L., Keevend, K., Muoth, C., Schönenberger, R., Diener, L., Wick, P., et al. (2018). An advanced human in vitro co-culture model for translocation studies across the placental barrier. Sci. Rep. 8:5388. doi: 10.1038/s41598-01823410-6

Albrecht, M., and Arck, P. C. (2020). Vertically transferred immunity in neonates: mothers, mechanisms and mediators. Front. Immunol. 11:555. doi: 10.3389/ fimmu.2020.00555

Aleyd, E., Heineke, M. H., and van Egmond, M. (2015). The era of the immunoglobulin A Fc receptor Fc $\alpha$ RI; its function and potential as target in disease. Immunol. Rev. 268, 123-138. doi: 10.1111/imr.12337

Alter, G., Ottenhoff, T. H. M., and Joosten, S. A. (2018). Antibody glycosylation in inflammation, disease and vaccination. Semin. Immunol. 39, 102-110. doi: 10.1016/j.smim.2018.05.003

Amirthalingam, G., Andrews, N., Campbell, H., Ribeiro, S., Kara, E., Donegan, K., et al. (2014). Effectiveness of maternal pertussis vaccination in England: An observational study. Lancet 384, 1521-1528. doi: 10.1016/S0140-6736(14) 60686-3

Amirthalingam, G., Campbell, H., Ribeiro, S., Fry, N. K., Ramsay, M., Miller, E., et al. (2016). Sustained effectiveness of the maternal pertussis immunization program in England 3 years following introduction. Clin. Infect. Dis. 63, S236-S243. doi: 10.1093/cid/ciw559

Andreas, N. J., Kampmann, B., and Mehring Le-Doare, K. (2015). Human breast milk: a review on its composition and bioactivity. Early Hum. Dev. 91, 629-635. doi: 10.1016/j.earlhumdev.2015.08.013

Araújo, E. D., Gonçalves, A. K., Cornetta, M. D. C., Cunha, H., Cardoso, M. L., Morais, S. S., et al. (2005). Evaluation of the secretory immunoglobulin A levels
Network (IMPRINT), which supported this research (MR/R005990/1 and MC_PC_17221). AS declares funding from Wellcome Trust Global Health Clinical Ph.D. Fellowship (220565/Z/20/Z). BK was funded by an MRC program grant (MC_UP_A900/1122; MC_UP_A900/115; and $\mathrm{MR} / \mathrm{K} 007602 / 1)$.

\section{ACKNOWLEDGMENTS}

We thank our IMPRINT members and other colleagues for their engaging discussions and important research contributions (including projects funded by the IMPRINT network) which have helped to inspire the topics covered by this review. Figure $\mathbf{1}$ image of a pregnant woman is courtesy of all-free-download.com and image of globe is reproduced with kind permission from TrueMitra Design Solutions (truemitra.com).

in the colostrum and milk of mothers of term and pre-term newborns. Braz. J. Infect. Dis. 9, 357-362. doi: 10.1590/s1413-86702005000500002

Atwell, J. E., Thumar, B., Formica, M. A., Robinson, L. J., Walsh, E. E., King, C. L., et al. (2019). Hypergammaglobulinemia and impaired transplacental transfer of respiratory syncytial virus antibody in Papua New Guinea. Pediatr. Infect. Dis. J. 38, e199-e202. doi: 10.1097/INF.000000000000 2364

Atwell, J. E., Thumar, B., Robinson, L. J., Tobby, R., Yambo, P., Ome-Kaius, M., et al. (2016). Impact of placental malaria and hypergammaglobulinemia on transplacental transfer of respiratory syncytial virus antibody in Papua New Guinea. J. Infect. Dis. 213, 423-431. doi: 10.1093/infdis/jiv401

Ausiello, C. M., Lande, R., Urbani, F., la Sala, A., Stefanelli, P., Salmaso, S., et al. (1999). Cell-mediated immune responses in four-year-old children after primary immunization with acellular pertussis vaccines. Infect. Immun. 67, 4064-4071.

Ballabio, C., Bertino, E., Coscia, A., Fabris, C., Fuggetta, D., Molfino, S., et al. (2007). Immunoglobulin-A profile in breast milk from mothers delivering full term and preterm infants. Int. J. Immunopathol. Pharmacol. 20, 119-128. doi: 10.1177/039463200702000114

Baxter, D., Ghebrehewet, S., Welfare, W., and Ding, D. C. D. (2010). Vaccinating premature infants in a Special Care Baby Unit in the UK: Results of a prospective, non-inferiority based, pragmatic case series study. Hum. Vaccin. 6, 512-520. doi: 10.4161/hv.6.6.11448

Bertley, F. M. N., Ibrahim, S. A., Libman, M., and Ward, B. J. (2004). Measles vaccination in the presence of maternal antibodies primes for a balanced humoral and cellular response to revaccination. Vaccine 23, 444-449. doi: 10. 1016/j.vaccine.2004.06.021

Bischoff, A. L., Følsgaard, N. V., Vissing, N. H., Birch, S., Brix, S., and Bisgaard, H. (2015). Airway mucosal immune-suppression in neonates of mothers receiving a(H1N1)pnd09 vaccination during pregnancy. Pediatr. Infect. Dis. J. 34, 84-90. doi: 10.1097/INF.0000000000000529

Bisseye, C., Van Der Sande, M., Morgan, W. D., Holder, A. A., Pinder, M., and Ismaili, J. (2009). Plasmodium falciparum infection of the placenta impacts on the Thelper type 1 (Th1)/Th2 balance of neonatal T cells through CD4 +CD25 + forkhead box P3 + regulatory T cells and interleukin-10. Clin. Exp. Immunol. 158, 287-293. doi: 10.1111/j.1365-2249.2009.04014.x

Bonhoeffer, J., Kochhar, S., Hirschfeld, S., Heath, P. T., Jones, C. E., Bauwens, J., et al. (2016). Global alignment of immunization safety assessment in pregnancy - The GAIA project. Vaccine 34, 5993-5997. doi: 10.1016/j.vaccine. 2016.07.006

Brair, M. E., Brabin, B., Milligan, P., Maxwell, S., and Hart, C. A. (1994). Reduced transfer of tetanus antibodies with placental malaria. Lancet 343, 208-209. doi: 10.1016/S0140-6736(94)90991-1 
Bruhns, P., Iannascoli, B., England, P., Mancardi, D. A., Fernandez, N., Jorieux, S., et al. (2009). Specificity and affinity of human Fc $\gamma$ receptors and their polymorphic variants for human IgG subclasses. Blood 113, 3716-3725. doi: 10.1182/blood-2008-09-179754

Burton, C. T., Goodall, R. L., Samri, A., Autran, B., Kelleher, A. D., Poli, G., et al. (2008). Restoration of anti-tetanus toxoid responses in patients initiating highly active antiretroviral therapy with or without a boost immunization: an INITIO substudy. Clin. Exp. Immunol. 152, 252-257. doi: 10.1111/j.1365-2249.2008. 03611.x

Cabinian, A., Sinsimer, D., Tang, M., Zumba, O., Mehta, H., Toma, A., et al. (2016). Transfer of maternal immune cells by breastfeeding: maternal cytotoxic t lymphocytes present in breast milk localize in the peyer's patches of the nursed infant. PLoS One 11:e0156762. doi: 10.1371/journal.pone.0156762

Calvert, A., and Jones, C. E. (2017). Placental transfer of antibody and its relationship to vaccination in pregnancy. Curr. Opin. Infect. Dis. 30, 268-273. doi: $10.1097 / \mathrm{QCO} .0000000000000372$

Carter, A. M. (2007). Animal models of human placentation - a review. Placenta 28, S41-S47. doi: 10.1016/j.placenta.2006.11.002

Chaithongwongwatthana, S., Yamasmit, W., Limpongsanurak, S., Lumbiganon, P., and Tolosa, J. E. (2015). Pneumococcal vaccination during pregnancy for preventing infant infection. Cochrane Database Syst. Rev. 1:CD004903. doi: 10.1002/14651858.CD004903.pub4

Chandak, G. R., Silver, M. J., Saffari, A., Lillycrop, K. A., Shrestha, S., Sahariah, S. A., et al. (2017). Protocol for the EMPHASIS study; epigenetic mechanisms linking maternal pre-conceptional nutrition and children's health in India and Sub-Saharan Africa. BMC Nutr. 3:81. doi: 10.1186/s40795-0170200-0

Chiappini, E., Petrolini, C., Caffarelli, C., Calvani, M., Cardinale, F., Duse, M., et al. (2019). Hexavalent vaccines in preterm infants: an update by Italian Society of Pediatric Allergy and Immunology jointly with the Italian Society of Neonatology. Ital. J. Pediatr. 45:145. doi: 10.1186/s13052-019-0742-7

Chung, A. W., and Alter, G. (2017). Systems serology: profiling vaccine induced humoral immunity against HIV. Retrovirology 14:57. doi: 10.1186/s12977-017$0380-3$

Conings, S., Amant, F., Annaert, P., and Van Calsteren, K. (2017). Integration and validation of the ex vivo human placenta perfusion model. J. Pharmacol. Toxicol. Methods 88, 25-31. doi: 10.1016/j.vascn.2017.05.002

Cumberland, P., Shulman, C. E., Maple, P. A. C., Bulmer, J. N., Dorman, E. K., Kawuondo, K., et al. (2007). Maternal HIV infection and placental malaria reduce transplacental antibody transfer and tetanus antibody levels in newborns in Kenya. J. Infect. Dis. 196, 550-557. doi: 10.1086/519845

da Silva Antunes, R., Babor, M., Carpenter, C., Khalil, N., Cortese, M., Mentzer, A. J., et al. (2018). Th1/Th17 polarization persists following whole-cell pertussis vaccination despite repeated acellular boosters. J. Clin. Invest. 128, 3853-3865. doi: 10.1172/JCI121309

Dangor, Z., Kwatra, G., Izu, A., Adrian, P., Van Niekerk, N., Cutland, C. L., et al. (2015). HIV-1 is associated with lower group B Streptococcus capsular and surface-protein IgG antibody levels and reduced transplacental antibody transfer in pregnant women. J. Infect. Dis. 212, 453-462. doi: 10.1093/infdis/ jiv064

Dangor, Z., Nunes, M. C., Kwatra, G., Lala, S. G., and Madhi, S. A. (2017). Vaccination of HIV-infected pregnant women: implications for protection of their young infants. Trop. Dis. Travel Med. Vaccines 3:1. doi: 10.1186/s40794016-0044-7

Dauby, N., Chamekh, M., Melin, P., Slogrove, A. L., and Goetghebuer, T. (2016). Increased risk of group B streptococcus invasive infection in HIV-exposed but uninfected infants: a review of the evidence and possible mechanisms. Front. Immunol. 7:505. doi: 10.3389/fimmu.2016.00505

Dauby, N., Goetghebuer, T., Kollmann, T. R., Levy, J., and Marchant, A. (2012). Uninfected but not unaffected: chronic maternal infections during pregnancy, fetal immunity, and susceptibility to postnatal infections. Lancet Infect. Dis. 12, 330-340. doi: 10.1016/S1473-3099(11)70341-3

De Agüero, M. G., Ganal-Vonarburg, S. C., Fuhrer, T., Rupp, S., Uchimura, Y., Li, H., et al. (2016). The maternal microbiota drives early postnatal innate immune development. Science 351, 1296-1302. doi: 10.1126/science.aad2571

de Bree, L. C. J., Koeken, V. A. C. M., Joosten, L. A. B., Aaby, P., Benn, C. S., van Crevel, R., et al. (2018). Non-specific effects of vaccines: current evidence and potential implications. Semin. Immunol. 39, 35-43. doi: 10.1016/j.smim.2018. 06.002

De Schutter, S., Maertens, K., Baerts, L., De Meester, I., Van Damme, P., and Leuridan, E. (2015). Quantification of vaccine-induced antipertussis toxin secretory IgA antibodies in breast milk: comparison of different vaccination strategies in women. Pediatr. Infect. Dis. J. 34, e149-e152. doi: 10.1097/INF. 0000000000000675

de Souza, E. G., Hara, C. C. P., Fagundes, D. L. G., de Queiroz, A. A., Morceli, G., Calderon, I. M. P., et al. (2016). Maternal-foetal diabetes modifies neonatal Fc receptor expression on human leucocytes. Scand. J. Immunol. 84, 237-244. doi: $10.1111 /$ sji.12466

Demers-Mathieu, V., Underwood, M. A., Beverly, R. L., Nielsen, S. D., and Dallas, D. C. (2018). Comparison of human milk immunoglobulin survival during gastric digestion between preterm and term infants. Nutrients 10:631. doi: 10. 3390/nu10050631

Depoix, C., Barret, L. A., Hubinont, C., and Debieve, F. (2013). Viability of primary term cytotrophoblast cell culture in normoxia and hypoxia. Mol. Hum. Reprod. 19, 29-34. doi: 10.1093/molehr/gas042

Doroudchi, M., Samsami Dehaghani, A., Emad, K., and Ghaderi, A. (2003). Placental transfer of rubella-specific IgG in fullterm and preterm newborns. Int. J. Gynecol. Obstet. 81, 157-162. doi: 10.1016/S0020-7292(02)00442-3

Eberhardt, C. S., Blanchard-Rohner, G., Lemaître, B., Boukrid, M., Combescure, C., Othenin-Girard, V., et al. (2016). Maternal immunization earlier in pregnancy maximizes antibody transfer and expected infant seropositivity against pertussis. Clin. Infect. Dis. 62, 829-836. doi: 10.1093/cid/ ciw027

Edwards, K. M. (2015). Maternal antibodies and infant immune responses to vaccines. Vaccine 33, 6469-6472. doi: 10.1016/j.vaccine.2015. 07.085

Einarsdottir, H. K., Stapleton, N. M., Scherjon, S., Andersen, J. T., Rispens, T., Van Der Schoot, C. E., et al. (2014). On the perplexingly low rate of transport of IgG2 across the human placenta. PLoS One 9:e108319. doi: 10.1371/journal. pone.0108319

Elias, D., Akuffo, H., Pawlowski, A., Haile, M., Schön, T., and Britton, S. (2005). Schistosoma mansoni infection reduces the protective efficacy of BCG vaccination against virulent Mycobacterium tuberculosis. Vaccine 23, 13261334. doi: $10.1016 /$ j.vaccine.2004.09.038

Englund, J. A. (2007). The influence of maternal immunization on infant immune responses. J. Comp. Pathol. 137, S16-S19. doi: 10.1016/j.jcpa.2007.04.006

Evans, C., Chasekwa, B., Ntozini, R., Humphrey, J. H., and Prendergast, A. J. (2016). Head circumferences of children born to HIV-infected and HIVuninfected mothers in Zimbabwe during the preantiretroviral therapy era. AIDS 30, 2323-2328. doi: 10.1097/QAD.0000000000001196

Falconer, O., Newell, M. L., and Jones, C. E. (2018). The effect of human immunodeficiency virus and Cytomegalovirus infection on infant responses to vaccines: a review. Front. Immunol. 9:328. doi: 10.3389/fimmu.2018.00328

Farquhar, C., Wamalwa, D., Selig, S., John-Stewart, G., Mabuka, J., Majiwa, M., et al. (2009). Immune responses to measles and tetanus vaccines among Kenyan human immunodeficiency virus type 1 (HIV-1)-infected children pre- and posthighly active antiretroviral therapy and revaccination. Pediatr. Infect. Dis. J. 28, 295-299. doi: 10.1097/INF.0b013e3181903ed3

Ferreira, R. B. R., Antunes, L. C. M., and Brett Finlay, B. (2010). Should the human microbiome be considered when developing vaccines? PLoS Pathog. 6:e1001190. doi: 10.1371/journal.ppat.1001190

Fischinger, S., Boudreau, C. M., Butler, A. L., Streeck, H., and Alter, G. (2019). Sex differences in vaccine-induced humoral immunity. Semin. Immunopathol. 41, 239-249. doi: 10.1007/s00281-018-0726-5

Fornara, C., Furione, M., Arossa, A., Gerna, G., and Lilleri, D. (2016). Comparative magnitude and kinetics of human cytomegalovirus-specific CD4+ and CD8+ T-cell responses in pregnant women with primary versus remote infection and in transmitting versus non-transmitting mothers: its utility for dating primary infection in pregnancy. J. Med. Virol. 88, 1238-1246. doi: 10.1002/jmv. 24449

Forsyth, K., Plotkin, S., and Tan, T. (2020). Pediatrics and Undefined Strategies to Decrease Pertussis Transmission to Infants. Available online at: https:// pediatrics.aappublications.org/content/135/6/e1475.abstract (accessed January 8, 2020). 
Fouda, G. G., Martinez, D. R., Swamy, G. K., and Permar, S. R. (2018). The impact of IgG transplacental transfer on early life immunity. Immunohorizons 2, 14-25. doi: 10.4049/immunohorizons.1700057

França, E. L., Calderon, I. D. M. P., Vieira, E. L., Morceli, G., and Honorio-França, A. C. (2012). Transfer of maternal immunity to newborns of diabetic mothers. Clin. Dev. Immunol. 2012:928187. doi: 10.1155/2012/928187

Francica, J. R., Zak, D. E., Linde, C., Siena, E., Johnson, C., Juraska, M., et al. (2017). Innate transcriptional effects by adjuvants on the magnitude, quality, and durability of HIV envelope responses in NHPs. Blood Adv. 1, 2329-2342. doi: 10.1182/bloodadvances.2017011411

Galassie, A. C., and Link, A. J. (2015). Proteomic contributions to our understanding of vaccine and immune responses. Proteomics Clin. Appl. 9, 972-989. doi: 10.1002/prca.201500054

Ganal-Vonarburg, S. C., Fuhrer, T., and Gomez de Agüero, M. (2017). Maternal microbiota and antibodies as advocates of neonatal health. Gut Microbes 8, 479-485. doi: 10.1080/19490976.2017.1299847

Garg, A. K., Desikan, R., and Dixit, N. M. (2019). Preferential presentation of high-affinity immune complexes in germinal centers can explain how passive immunization improves the humoral response. Cell Rep. 29, 3946-3957.e5.

Gensollen, T., Iyer, S. S., Kasper, D. L., and Blumberg, R. S. (2016). How colonization by microbiota in early life shapes the immune system. Science 352, 539-544. doi: 10.1126/science.aad9378

Gent, V., Waihenya, R., Kamau, L., Nyakundi, R., Ambala, P., Kariuki, T., et al. (2019). An investigation into the role of chronic Schistosoma mansoni infection on Human Papillomavirus (HPV) vaccine induced protective responses. PLoS Negl. Trop. Dis. 13:e0007704. doi: 10.1371/journal.pntd.0007704

Geuking, M. B., McCoy, K. D., and Macpherson, A. J. (2012). The function of secretory IgA in the context of the intestinal continuum of adaptive immune responses in host-microbial mutualism. Semin. Immunol. 24, 36-42. doi: 10. 1016/j.smim.2011.11.005

Gill, T. J., Repetti, C. F., Metlay, L. A., Rabin, B. S., Taylor, F. H., Thompson, D. S., et al. (1983). Transplacental immunization of the human fetus to tetanus by immunization of the mother. J. Clin. Invest. 72, 987-996. doi: 10.1172/ JCI111071

Gkentzi, D., Katsakiori, P., Marangos, M., Hsia, Y., Amirthalingam, G., Heath, P. T., et al. (2017). Maternal vaccination against pertussis: a systematic review of the recent literature. Arch. Dis. Child. Fetal Neonatal. Ed. 102, F456-F463. doi: 10.1136/archdischild-2016-312341

Gonçalves, G., Cutts, F. T., Hills, M., Rebelo-Andrade, H., Trigo, F. A., and Barros, H. (1999). Transplacental transfer of measles and total IgG. Epidemiol. Infect. 122, 273-279. doi: 10.1017/s0950268899002046

Goonatilleke, E., Smilowitz, J. T., Mariño, K. V., German, B. J., Lebrilla, C. B., and Barboza, M. (2019). Immunoglobulin A N-glycosylation presents important body fluid-specific variations in lactating mothers. Mol. Cell. Proteomics 18, 2165-2177. doi: 10.1074/mcp.RA119.001648

Gregory, K. E., and Walker, W. A. (2013). Immunologic factors in human milk and disease prevention in the preterm infant. Curr. Pediatr. Rep. 1:10.1007/s40124013-0028-2. doi: 10.1007/s40124-013-0028-2

Grigsby, P. L. (2016). Animal models to study placental development and function throughout normal and dysfunctional human pregnancy. Semin. Reprod. Med. 34, 11-16. doi: 10.1055/s-0035-1570031

Gupta, A., Mathad, J. S., Yang, W. T., Singh, H. K., Gupte, N., Mave, V., et al. (2014). Maternal pneumococcal capsular IgG antibodies and transplacental transfer are low in South Asian HIV-infected mother-infant pairs. Vaccine 32, 1466-1472. doi: 10.1016/j.vaccine.2014.01.033

Guttmacher, A. E., Maddox, Y. T., and Spong, C. Y. (2014). The human placenta project: placental structure, development, and function in real time. Placenta 35, 303-304. doi: 10.1016/j.placenta.2014.02.012

Halperin, B. A., Morris, A., MacKinnon-Cameron, D., Mutch, J., Langley, J. M., McNeil, S. A., et al. (2011). Kinetics of the antibody response to tetanusdiphtheria-acellular pertussis vaccine in women of childbearing age and postpartum women. Clin. Infect. Dis. 53, 885-892. doi: 10.1093/cid/cir538

Hartter, H. K., Oyedele, O. I., Dietz, K., Kreis, S., Hoffman, J. P., and Muller, C. P. (2000). Placental transfer and decay of maternally acquired antimeasles antibodies in Nigerian children. Pediatr. Infect. Dis. J. 19, 635-641. doi: 10.1097/ 00006454-200007000-00010

Healy, C. M., Rench, M. A., and Baker, C. J. (2013). Importance of timing of maternal combined tetanus, diphtheria, and acellular pertussis (Tdap) immunization and protection of young infants. Clin. Infect. Dis. 56, 539-544. doi: $10.1093 /$ cid/cis923

Herberts, C., Melgert, B., van der Laan, J. W., and Faas, M. (2010). New adjuvanted vaccines in pregnancy: what is known about their safety? Expert Rev. Vaccines 9, 1411-1422. doi: 10.1586/erv.10.133

Heyderman, R. S., Madhi, S. A., French, N., Cutland, C., Ngwira, B., Kayambo, D., et al. (2016). Group B streptococcus vaccination in pregnant women with or without HIV in Africa: a non-randomised phase 2, open-label, multicentre trial. Lancet Infect. Dis. 16, 546-555. doi: 10.1016/S1473-3099(15)0 0484-3

Hoang, H. T. T., Leuridan, E., Maertens, K., Nguyen, T. D., Hens, N., Vu, N. H., et al. (2016). Pertussis vaccination during pregnancy in Vietnam: results of a randomized controlled trial Pertussis vaccination during pregnancy. Vaccine 34, 151-159. doi: 10.1016/j.vaccine.2015.10.098

Holder, B., Jones, T., Sancho Shimizu, V., Rice, T. F., Donaldson, B., Bouqueau, M., et al. (2016). Macrophage exosomes induce placental inflammatory cytokines: a novel mode of maternal-placental messaging. Traffic 17, 168-178. doi: 10.1111/ tra. 12352

Honda-Okubo, Y., Kolpe, A., Li, L., and Petrovsky, N. (2014). A single immunization with inactivated $\mathrm{H} 1 \mathrm{~N} 1$ influenza vaccine formulated with delta inulin adjuvant (AdvaxTM) overcomes pregnancy-associated immune suppression and enhances passive neonatal protection. Vaccine 32, 4651-4659. doi: 10.1016/j.vaccine.2014.06.057

Huckle, W. R. (2017). Cell- and tissue-based models for study of placental development. Prog. Mol. Biol. Transl. Sci. 145, 29-37. doi: 10.1016/bs.pmbts. 2016.12.002

Huda, M. N., Ahmad, S. M., Alam, M. J., Khanam, A., Kalanetra, K. M., Taft, D. H., et al. (2019). Bifidobacterium abundance in early infancy and vaccine response at 2 years of age. Pediatrics 143:e20181489.

Hutson, J. R., Garcia-Bournissen, F., Davis, A., and Koren, G. (2011). The human placental perfusion model: a systematic review and development of a model to predict in vivo transfer of therapeutic drugs. Clin. Pharmacol. Ther. 90, 67-76. doi: 10.1038/clpt.2011.66

Isabel de Moraes-Pinto, M., Almeida, A. C. M., Kenj, G., Filgueiras, T. E., Tobias, W., Santos, A. M. N., et al. (1996). Placental transfer and maternally acquired neonatal IgG immunity in human immunodeficiency virus infection. J. Infect. Dis. 173, 1077-1084. doi: 10.1093/infdis/173.5. 1077

Janoff, E. N., Gustafson, C., and Frank, D. N. (2012). The world within: living with our microbial guests and guides. Transl. Res. 160, 239-245. doi: 10.1016/j.trsl. 2012.05.005

Jarvis, J. R., Dorey, R. B., Warricker, F. D. M., Alwan, N. A., and Jones, C. E. (2020). The effectiveness of influenza vaccination in pregnancy in relation to child health outcomes: systematic review and meta-analysis. Vaccine 38, 1601-1613. doi: 10.1016/j.vaccine.2019.12.056

Jennewein, M. F., Abu-Raya, B., Jiang, Y., Alter, G., and Marchant, A. (2017). Transfer of maternal immunity and programming of the newborn immune system. Semin. Immunopathol. 39, 605-613. doi: 10.1007/s00281-017-0653-x

Jennewein, M. F., Goldfarb, I., Dolatshahi, S., Cosgrove, C., Noelette, F. J., Krykbaeva, M., et al. (2019). Fc glycan-mediated regulation of placental antibody transfer. Cell 178, 202-215.e14. doi: 10.1016/j.cell.2019. 05.044

Jiang, B., Jones, S., Groome, M. J., Velasquez, D., Moon, S.-S., Parashar, U. D., et al. (2014). Effect of breastfeeding on immunogenicity of oral live-attenuated human rotavirus vaccine: a randomized trial in HIV-uninfected infants in Soweto, South Africa. Bull. World Health Organ. 92, 238-245. doi: 10.2471/blt. 13.128066

Jones, C., Pollock, L., Barnett, S. M., Battersby, A., and Kampmann, B. (2013). Specific antibodies against vaccine-preventable infections: a mother-infant cohort study. BMJ Open 3:e002473. doi: 10.1136/bmjopen-2012-002473

Jones, C., Pollock, L., Barnett, S. M., Battersby, A., and Kampmann, B. (2014). The relationship between concentration of specific antibody at birth and subsequent response to primary immunization. Vaccine 32, 996-1002. doi: 10.1016/j.vaccine.2013.11.104

Jones, C. E., Naidoo, S., De Beer, C., Esser, M., Kampmann, B., and Hesseling, A. C. (2011). Maternal HIV infection and antibody responses against vaccinepreventable diseases in uninfected infants. JAMA 305, 576-584. doi: 10.1001/ jama.2011.100 
Jones, V., Wilks, M., Johnson, G., Warwick, S., Hennessey, E., Kempley, S., et al. (2010). The use of molecular techniques for bacterial detection in the analysis of gastric aspirates collected from infants on the first day of life. Early Hum. Dev. 86, 167-170. doi: 10.1016/J.EARLHUMDEV.2009.11.005

Kandeil, W., Savic, M., Ceregido, M. A., Guignard, A., Kuznetsova, A., and Mukherjee, P. (2020). Immune interference (blunting) in the context of maternal immunization with Tdap-containing vaccines: is it a class effect? Expert Rev. Vaccines 19, 341-352. doi: 10.1080/14760584.2020.1749597

Kernéis, S., Launay, O., Turbelin, C., Batteux, F., Hanslik, T., and Boëlle, P.-Y. (2014). Long-term immune responses to vaccination in HIV-infected patients: a systematic review and meta-analysis. Clin. Infect. Dis. 58, 1130-1139. doi: $10.1093 /$ cid/cit937

Kim, D., Huey, D., Oglesbee, M., and Niewiesk, S. (2011). Insights into the regulatory mechanism controlling the inhibition of vaccine-induced seroconversion by maternal antibodies. Blood 117, 6143-6151. doi: 10.1182/ blood-2010-11-320317

Kinder, J. M., Jiang, T. T., Ertelt, J. M., Xin, L., Strong, B. S., Shaaban, A. F., et al. (2015). Cross-generational reproductive fitness enforced by microchimeric maternal cells. Cell 162, 505-515. doi: 10.1016/j.cell.2015.07.006

Kinder, J. M., Stelzer, I. A., Arck, P. C., and Way, S. S. (2017a). Immunological implications of pregnancy-induced microchimerism. Nat. Rev. Immunol. 17, 483-494. doi: 10.1038/nri.2017.38

Kinder, J. M., Stelzer, I. A., Arck, P. C., and Way, S. S. (2017b). Reply: breastfeedingrelated maternal microchimerism. Nat. Rev. Immunol. 17, 730-731. doi: 10. 1038/nri.2017.117

Kirmiz, N., Robinson, R. C., Shah, I. M., Barile, D., and Mills, D. A. (2018). Milk glycans and their interaction with the infant-gut microbiota. Annu. Rev. Food Sci. Technol. 9, 429-450. doi: 10.1146/annurev-food-030216-030207

Koch, M., Reiner, G., Lugo, K., and Cell, L. K. (2016). Maternal IgG and IgA Antibodies Dampen Mucosal T Helper Cell Responses in Early Life. Available online at: https://www.sciencedirect.com/science/article/pii/ S0092867416305001 (accessed May 27, 2020).

Kollmann, T. R., Kampmann, B., Mazmanian, S. K., Marchant, A., and Levy, O. (2017). Protecting the newborn and young infant from infectious diseases: lessons from immune ontogeny. Immunity 46, 350-363. doi: 10.1016/j.immuni. 2017.03.009

Kollmann, T. R., Marchant, A., and Way, S. S. (2020). Vaccination strategies to enhance immunity in neonates. Science 368, 612-615. doi: 10.1126/science. aaz9447

Krammer, F., García-Sastre, A., and Palese, P. (2018). Is it possible to develop a "universal" influenza virus vaccine: potential target antigens and critical aspects for a universal influenza vaccine. Cold Spring Harb. Perspect. Biol. 10:a028845. doi: 10.1101/cshperspect.a028845

Ladhani, S. N., Andrews, N. J., Southern, J., Jones, C. E., Amirthalingam, G., Waight, P. A., et al. (2015). Antibody responses after primary immunization in infants born to women receiving a Pertussis-containing vaccine during pregnancy: single arm observational study with a historical comparator. Clin. Infect. Dis. 61, 1637-1644. doi: 10.1093/cid/civ695

Langel, S. N., Otero, C. E., Martinez, D. R., and Permar, S. R. (2020). Maternal gatekeepers: how maternal antibody Fc characteristics influence passive transfer and infant protection. PLoS Pathog. 16:e1008303. doi: 10.1371/journal.ppat. 1008303

Laris-González, A., Bernal-Serrano, D., Jarde, A., and Kampmann, B. (2020). Safety of administering live vaccines during pregnancy: a systematic review and metaanalysis of pregnancy outcomes. Vaccines 8:124. doi: 10.3390/vaccines 8010124

Lee, L. Y. Y., Izzard, L., and Hurt, A. C. (2018). A review of DNA vaccines against influenza. Front. Immunol. 9:1568. doi: 10.3389/fimmu.2018.01568

Le Doare, K., Allen, L., Kampmann, B., Heath, P. T., Taylor, S., Hesseling, A. C., et al. (2015). Anti-Group B Streptococcus antibody in infants born to mothers with human immunodeficiency virus (HIV) infection. Vaccine 33, 621-627. doi: 10.1016/j.vaccine.2014.12.025

Le Doare, K., Bellis, K., Faal, A., Birt, J., Munblit, D., Humphries, H., et al. (2017). SIgA, TGF- $\beta 1$, IL-10, and TNF $\alpha$ in colostrum are associated with infant group B Streptococcus colonization. Front. Immunol. 8:1269. doi: 10.3389/fimmu.2017. 01269

Le Doare, K., Holder, B., Bassett, A., and Pannaraj, P. S. (2018). Mother's milk: a purposeful contribution to the development of the infant microbiota and immunity. Front. Immunol. 9:361. doi: 10.3389/fimmu.2018.00361
Lee, A. H., Shannon, C. P., Amenyogbe, N., Bennike, T. B., Diray-Arce, J., Idoko, O. T., et al. (2019). Dynamic molecular changes during the first week of human life follow a robust developmental trajectory. Nat. Commun. 10:1092. doi: 10.1038/s41467-019-08794-x

Lee, K. H., Gordon, A., Shedden, K., Kuan, G., Ng, S., Balmaseda, A., et al. (2019). The respiratory microbiome and susceptibility to influenza virus infection. PLoS One 14:e0207898. doi: 10.1371/journal.pone.0207898

Li, S., Sullivan, N. L., Rouphael, N., Yu, T., Banton, S., Maddur, M. S., et al. (2017). Metabolic phenotypes of response to vaccination in humans. Cell 169, 862-877.e17. doi: 10.1016/j.cell.2017.04.026

Lilleri, D., Fornara, C., Furione, M., Zavattoni, M., Revello, M. G., and Gerna, G. (2007). Development of human cytomegalovirus-specific T cell immunity during primary infection of pregnant women and its correlation with virus transmission to the fetus. J. Infect. Dis. 195, 1062-1070. doi: 10.1086/512245

Lindsey, B., Jones, C., and Kampmann, B. (2012). Bridging the gap: maternal immunisation as a means to reduce neonatal deaths from infectious diseases. Pathog. Glob. Health 106, 137-138. doi: 10.1179/204777312X13462106637684

Lingblom, C. M. D., Kowli, S., Swaminathan, N., Maecker, H. T., and Lambert, S. L. (2018). Baseline immune profile by CyTOF can predict response to an investigational adjuvanted vaccine in elderly adults. J. Transl. Med. 16:153. doi: 10.1186/s12967-018-1528-1

Linnik, J. E., and Egli, A. (2016). Impact of host genetic polymorphisms on vaccine induced antibody response. Hum. Vaccines Immunother. 12, 907-915. doi: 10.1080/21645515.2015.1119345

Liu, L., Oza, S., Hogan, D., Chu, Y., Perin, J., Zhu, J., et al. (2016). Global, regional, and national causes of under-5 mortality in 2000-15: an updated systematic analysis with implications for the sustainable development goals. Lancet 388 , 3027-3035. doi: 10.1016/S0140-6736(16)31593-8

Locks, L. M., Manji, K. P., Kupka, R., Liu, E., Kisenge, R., McDonald, C. M., et al. (2017). High burden of morbidity and mortality but not growth failure in infants exposed to but uninfected with human immunodeficiency virus in Tanzania. J. Pediatr. 180, 191-199.e2. doi: 10.1016/j.jpeds.2016. 09.040

Lofano, G., Gorman, M. J., Yousif, A. S., Yu, W. H., Fox, J. M., Dugast, A. S., et al. (2018). Antigen-specific antibody Fc glycosylation enhances humoral immunity via the recruitment of complement. Sci. Immunol. 3:eaat7796. doi: 10.1126/sciimmunol.aat7796

López-Sanguos, C., Rivero Calle, I., Rodriguez Tenreiro, C., Raguindin, P. F., and Martinón-Torres, F. (2019). Safety and immunogenicity of pneumococcal conjugate vaccines in preterm infants. Expert Opin. Drug Saf. 18, 253-259. doi: 10.1080/14740338.2019.1597849

Lozano, N. A., Lozano, A., Marini, V., Saranz, R. J., Blumberg, R. S., Baker, K., et al. (2018). Expression of FcRn receptor in placental tissue and its relationship with IgG levels in term and preterm newborns. Am. J. Reprod. Immunol. 80:e12972. doi: 10.1111/aji.12972

Lynn, D. J., and Pulendran, B. (2018). The potential of the microbiota to influence vaccine responses. J. Leukoc. Biol. 103, 225-231. doi: 10.1189/jlb.5MR0617$216 \mathrm{R}$

Macpherson, A. J., De Agüero, M. G., and Ganal-Vonarburg, S. C. (2017). How nutrition and the maternal microbiota shape the neonatal immune system. Nat. Rev. Immunol. 17, 508-517. doi: 10.1038/nri.2017.58

Madhi, S. A., Cutland, C. L., Kuwanda, L., Weinberg, A., Hugo, A., Jones, S., et al. (2014). Influenza vaccination of pregnant women and protection of their infants. N. Engl. J. Med. 371, 918-931. doi: 10.1056/NEJMoa1401480

Maertens, K., De Schutter, S., Braeckman, T., Baerts, L., Van Damme, P., De Meester, I., et al. (2014). Breastfeeding after maternal immunisation during pregnancy: providing immunological protection to the newborn: a review. Vaccine 32, 1786-1792. doi: 10.1016/j.vaccine.2014.01.083

Maertens, K., Tran, T. M. P., Hens, N., Van Damme, P., and Leuridan, E. (2017). Effect of prepregnancy pertussis vaccination in young infants. J. Infect. Dis. 215, 1855-1861. doi: 10.1093/infdis/jix176

Mahan, A. E., Jennewein, M. F., Suscovich, T., Dionne, K., Tedesco, J., Chung, A. W., et al. (2016). Antigen-specific antibody Glycosylation is regulated via vaccination. PLoS Pathog. 12:e1005456. doi: 10.1371/journal.ppat.1005456

Mahan, A. E., Mattoo, H., Dionne, K., Tedesco, J., Pillai, S., and Alter, G. (2014). IgG glycosylation is programmed and remembered after immunization with TLR stimulating Adjuvants. AIDS Res. Hum. Retroviruses 30, A65-A65. doi: 10.1089/aid.2014.5118.abstract 
Maidji, E., McDonagh, S., Genbacev, O., Tabata, T., and Pereira, L. (2006). Maternal antibodies enhance or prevent cytomegalovirus infection in the placenta by neonatal Fc receptor-mediated transcytosis. Am. J. Pathol. 168, 1210-1226. doi: 10.2353/ajpath.2006.050482

Malhotra, I., Dent, A., Mungai, P., Wamachi, A., Ouma, J. H., Narum, D. L., et al. (2009). Can prenatal malaria exposure produce an immune tolerant phenotype: A prospective birth cohort study in Kenya. PLoS Med. 6:e1000116. doi: 10.1371/journal.pmed.1000116

Marchant, A., Sadarangani, M., Garand, M., Dauby, N., Verhasselt, V., Pereira, L., et al. (2017). Maternal immunisation: collaborating with mother nature. Lancet Infect. Dis. 17, e197-e208. doi: 10.1016/S1473-3099(17)30229-3

Martinez, D. R., Fong, Y., Li, S. H., Yang, F., Jennewein, M. F., Weiner, J. A., et al. (2019). Fc characteristics mediate selective placental transfer of IgG in HIV-infected women. Cell 178, 190-201.e11. doi: 10.1016/j.cell.2019.05.046

Martinez, D. R., Fouda, G. G., Peng, X., Ackerman, M. E., and Permar, S. R. (2018). Noncanonical placental Fc receptors: What is their role in modulating transplacental transfer of maternal IgG? PLoS Pathog. 14:e1007161. doi: 10. 1371/journal.ppat.1007161

Mattu, T. S., Pleass, R. J., Willis, A. C., Kilian, M., Wormald, M. R., Lellouch, A. C., et al. (1998). The glycosylation and structure of human serum IgA1, Fab, and $\mathrm{Fc}$ regions and the role of $\mathrm{N}$-glycosylation on $\mathrm{Fc} \alpha$ receptor interactions. J. Biol. Chem. 273, 2260-2272. doi: 10.1074/jbc.273.4.2260

May, K., Grube, M., Malhotra, I., Long, C. A., Singh, S., Mandaliya, K., et al. (2009). Antibody-dependent transplacental transfer of malaria blood-stage antigen using a human ex vivo placental perfusion model. PLoS One 4:e7986. doi: 10.1371/journal.pone.0007986

Mika, M., Mack, I., Korten, I., Qi, W., Aebi, S., Frey, U., et al. (2015). Dynamics of the nasal microbiota in infancy: a prospective cohort study. J. Allergy Clin. Immunol. 135, 905-912.e11. doi: 10.1016/j.jaci.2014.12.1909

Mika, M., Maurer, J., Korten, I., Allemann, A., Aebi, S., Brugger, S. D., et al. (2017). Influence of the pneumococcal conjugate vaccines on the temporal variation of pneumococcal carriage and the nasal microbiota in healthy infants: a longitudinal analysis of a case-control study. Microbiome 5:85. doi: 10.1186/ s40168-017-0302-6

Miller, R. K., Genbacev, O., Turner, M. A., Aplin, J. D, Caniggia, I., and Huppertz, B. (2005). Human placental explants in culture: approaches and assessments. Placenta 26, 439-448. doi: 10.1016/j.placenta.2004.10.002

Moir, S., Buckner, C. M., Ho, J., Wang, W., Chen, J., Waldner, A. J., et al. (2010). B cells in early and chronic HIV infection: evidence for preservation of immune function associated with early initiation of antiretroviral therapy. Blood 116, 5571-5579. doi: 10.1182/blood-2010-05-285528

Molès, J. P., Tuaillon, E., Kankasa, C., Bedin, A. S., Nagot, N., Marchant, A., et al. (2017). Breastfeeding-related maternal microchimerism. Nat. Rev. Immunol. 17:729. doi: 10.1038/nri.2017.115

Moore, S. E., Collinson, A. C., Fulford, A. J. C., Jalil, F., Siegrist, C. A., Goldblatt, D., et al. (2006). Effect of month of vaccine administration on antibody responses in the Gambia and Pakistan. Trop. Med. Int. Heal. 11, 1529-1541. doi: 10.1111/ j.1365-3156.2006.01700.x

Moro, P. L., and Sukumaran, L. (2017). Cholera vaccination: pregnant women excluded no more. Lancet Infect. Dis. 17, 469-470. doi: 10.1016/S1473-3099(17) 30055-5

Munoz, F. M. (2018). Current challenges and achievements in maternal immunization research. Front. Immunol. 9:436. doi: 10.3389/fimmu.2018. 00436

Munoz, F. M., Bond, N. H., Maccato, M., Pinell, P., Hammill, H. A., Swamy, G. K., et al. (2014). Safety and immunogenicity of tetanus diphtheria and acellular pertussis (Tdap) immunization during pregnancy in mothers and infants: a randomized clinical trial. JAMA 311, 1760-1769. doi: 10.1001/jama.2014. 3633

Munoz, F. M., Englund, J. A., Cheesman, C. C., Maccato, M. L., Pinell, P. M., Nahm, M. H., et al. (2001). Maternal immunization with pneumococcal polysaccharide vaccine in the third trimester of gestation. Vaccine 20, 826-837. doi: 10.1016/ s0264-410x(01)00397-8

Munoz, F. M., and Jamieson, D. J. (2019). Maternal Immunization. Obstet. Gynecol. 133, 739-753. doi: 10.1097/AOG.0000000000003161

Muňoz, F. M., Swamy, G. K., Hickman, S. P., Agrawal, S., Piedra, P. A., Glenn, G. M., et al. (2019). Safety and immunogenicity of a respiratory syncytial virus fusion $(\mathrm{F})$ protein nanoparticle vaccine in healthy third-trimester pregnant women and their infants. J. Infect. Dis. 220, 1802-1815. doi: 10.1093/infdis/ jiz390

Munoz, F. M., Van Damme, P., Dinleyici, E., Clarke, E., Kampmann, B., Heath, P. T., et al. (2018). The fourth international neonatal and maternal immunization symposium (INMIS 2017): toward integrating maternal and infant immunization programs. mSphere 3:e00221-18. doi: 10.1128/msphere. 00221- 18

Mwila, K., Chilengi, R., Simuyandi, M., Permar, S. R., and Becker-Dreps, S. (2017). Contribution of maternal immunity to decreased rotavirus vaccine performance in low-and middle-income countries. Clin. Vaccine Immunol. 24:e00405-16. doi: 10.1128/CVI.00405-16

Naidu, M. A., Muljadi, R., Davies-Tuck, M. L., Wallace, E. M., and Giles, M. L. (2016). The optimal gestation for pertussis vaccination during pregnancy: a prospective cohort study. Am. J. Obstet. Gynecol. 215, 237.e1-237.e6. doi: 10. 1016/j.ajog.2016.03.002

Nakaya, H. I., and Pulendran, B. (2015). Vaccinology in the era of high-throughput biology. Philos. Trans. R. Soc. B Biol. Sci. 370:20140146. doi: 10.1098/rstb.2014. 0146

Netea, M. G., and van der Meer, J. W. M. (2017). Trained immunity: an ancient way of remembering. Cell Host Microbe 21, 297-300. doi: 10.1016/j.chom.2017. 02.003

Newport, M. J. (2015). The genetic regulation of infant immune responses to vaccination. Front. Immunol. 6:18. doi: 10.3389/fimmu.2015. 00018

Nguyen, Q. N., Himes, J. E., Martinez, D. R., and Permar, S. R. (2016). The impact of the gut microbiota on humoral immunity to pathogens and vaccination in early infancy. PLoS Pathog. 12:e1005997. doi: 10.1371/journal.ppat.100 5997

Nieminen, H., Rinta-Kokko, H., Jokinen, J., Puumalainen, T., Moreira, M., Borys, D., et al. (2019). Effectiveness of the 10-valent pneumococcal conjugate vaccine among girls, boys, preterm and low-birth-weight infants - Results from a randomized, double-blind vaccine trial. Vaccine 37, 3715-3721. doi: 10.1016/ j.vaccine.2019.05.033

Niewiesk, S. (2014). Maternal antibodies: clinical significance, mechanism of interference with immune responses, and possible vaccination strategies. Front. Immunol. 5:446. doi: 10.3389/fimmu.2014.00446

Nunes, M. C., Cutland, C. L., Dighero, B., Bate, J., Jones, S., Hugo, A., et al. (2015). Kinetics of Hemagglutination-Inhibiting Antibodies Following Maternal Influenza Vaccination Among Mothers With and Those Without HIV Infection and Their Infants. J Infect Dis. 212, 1976-1987. doi: 10.1093/infdis/ jiv339

Ober, R. J., Martinez, C., Lai, X., Zhou, J., and Ward, E. S. (2004). Exocytosis of IgG as mediated by the receptor, FcRn: an analysis at the single-molecule level. Proc. Natl. Acad. Sci. USA. 101, 11076-11081. doi: 10.1073/pnas.0402970101

Oddy, W. H. (2002). Long-term health outcomes and mechanisms associated with breastfeeding. Expert Rev. Pharmacoecon. Outcomes Res. 2, 161-177. doi: 10. 1586/14737167.2.2.161

O’Dempsey, T. J., McArdle, T., Ceesay, S. J., Banya, W. A., Demba, E., Secka, O., et al. (1996). Immunization with a pneumococcal capsular polysaccharide vaccine during pregnancy. Vaccine 14, 963-970. doi: 10.1016/0264-410x(96) 00009-6

Odorizzi, P. M., Jagannathan, P., McIntyre, T. I., Budker, R., Prahl, M., Auma, A., et al. (2018). In utero priming of highly functional effector $\mathrm{T}$ cell responses to human malaria. Sci. Transl. Med. 10:eaat6176. doi: 10.1126/scitranslmed. aat6176

Ogolla, S., Daud, I. I., Asito, A. S., Sumba, O. P., Ouma, C., Vulule, J., et al. (2015). Reduced transplacental transfer of a subset of Epstein-Barr virus-specific antibodies to neonates of mothers infected with Plasmodium falciparum malaria during pregnancy. Clin. Vaccine Immunol. 22, 1197-1205. doi: 10.1128/ CVI.00270-15

Ojal, J., Hammitt, L. L., Gaitho, J., Scott, J. A. G., and Goldblatt, D. (2017). Pneumococcal conjugate vaccine induced IgG and nasopharyngeal carriage of pneumococci: hyporesponsiveness and immune correlates of protection for carriage. Vaccine 35, 4652-4657. doi: 10.1016/j.vaccine.2017. 05.088

Okala, S. G., Darboe, M. K., Sosseh, F., Sonko, B., Faye-Joof, T., Prentice, A. M., et al. (2019). Impact of nutritional supplementation during pregnancy on antibody responses to diphtheria-tetanus-pertussis vaccination in infants: a 
randomised trial in The Gambia. PLoS Med. 16:e1002854. doi: 10.1371/journal. pmed.1002854

Okazaki, A., Shoji-Hosaka, E., Nakamura, K., Wakitani, M., Uchida, K., Kakita, S., et al. (2004). Fucose depletion from human IgG1 oligosaccharide enhances binding enthalpy and association rate between IgG1 and Fc $\gamma$ RIIIa. J. Mol. Biol. 336, 1239-1249. doi: 10.1016/j.jmb.2004.01.007

Okoko, B. J., Wesumperuma, L. H., Ota, M. O. C., Pinder, M., Banya, W., Gomez, S. F., et al. (2001). The influence of placental malaria infection and maternal hypergammaglobulinemia on transplacental transfer of antibodies and IgG subclasses in a rural west african population. J. Infect. Dis. 184, 627-632. doi: $10.1086 / 322808$

Okoko, J. B., Wesumperuma, H. L., and Hart, C. A. (2001). The influence of prematurity and low birthweight on transplacental antibody transfer in a rural West African population. Trop. Med. Int. Heal. 6, 529-534. doi: 10.1046/j.13653156.2001.00741.x

Omeñaca, F., Vázquez, L., Garcia-Corbeira, P., Mesaros, N., Hanssens, L., Dolhain, J., et al. (2018). Immunization of preterm infants with GSK's hexavalent combined diphtheria-tetanus-acellular pertussis-hepatitis B-inactivated poliovirus-Haemophilus influenzae type b conjugate vaccine: a review of safety and immunogenicity. Vaccine 36, 986-996. doi: 10.1016/j.vaccine.2018.01.005

Orendi, K., Kivityb, V., Sammar, M., Grimpel, Y., Gonen, R., Meiri, H., et al. (2011). Placental and trophoblastic in vitro models to study preventive and therapeutic agents for preeclampsia. Placenta 32, S49-S54. doi: 10.1016/j.placenta.2010.11. 023

Orije, M. R. P., Maertens, K., Corbière, V., Wanlapakorn, N., Van Damme, P., Leuridan, E., et al. (2020). The effect of maternal antibodies on the cellular immune response after infant vaccination: a review. Vaccine 38, 20-28. doi: 10.1016/j.vaccine.2019.10.025

Palmeira, P., and Carneiro-Sampaio, M. (2016). Immunology of breast milk. Rev. Assoc. Med. Bras. 62, 584-593. doi: 10.1590/1806-9282.62.06.584

Palmeira, P., Quinello, C., Silveira-Lessa, A. L., Zago, C. A., and Carneiro-Sampaio, M. (2012). IgG placental transfer in healthy and pathological pregnancies. Clin. Dev. Immunol. 2012:985646. doi: 10.1155/2012/985646

Parker, E. P. K., Ramani, S., Lopman, B. A., Church, J. A., Iturriza-Gómara, M., Prendergast, A. J., et al. (2018). Causes of impaired oral vaccine efficacy in developing countries. Future Microbiol. 13, 97-118. doi: 10.2217/fmb-20170128

Patel, C. D., Backes, I. M., Taylor, S. A., Jiang, Y., Marchant, A., Pesola, J. M., et al. (2019a). Maternal immunization confers protection against neonatal herpes simplex mortality and behavioral morbidity. Sci. Transl. Med. 11:eaau6039. doi: 10.1126/scitranslmed.aau6039

Patel, S. M., Jallow, S., Boiditswe, S., Madhi, S. A., Feemster, K. A., Steenhoff, A. P., et al. (2019b). Placental transfer of respiratory syncytial virus antibody among HIV-exposed, uninfected infants. J. Pediatric Infect. Dis. Soc. doi: 10.1093/jpids/ piz056 [Epub ahead of print].

Patel, C. D., Taylor, S. A., Mehrbach, J., Awasthi, S., Friedman, H. M., and Leib, D. A. (2020). Trivalent glycoprotein subunit vaccine prevents neonatal herpes simplex virus mortality and morbidity. J. Virol. 94:e02163-19. doi: 10.1128/jvi. 02163-19

PATH (2018). A Roadmap for Advancing RSV Maternal Immunization. Seattle: PATH.

Pereira, L., and Maidji, E. (2008). Cytomegalovirus infection in the human placenta: maternal immunity and developmentally regulated receptors on trophoblasts converge. Curr. Top. Microbiol. Immunol. 325, 383-395. doi: 10. 1007/978-3-540-77349-8_21

Permar, S. R., Schleiss, M. R., and Plotkin, S. A. (2018). Advancing our understanding of protective maternal immunity as a guide for development of vaccines to reduce congenital cytomegalovirus infections. J. Virol. 92:e00030-18. doi: $10.1128 /$ jvi.00030-18

Pezeshki, A., Ovsyannikova, I. G., McKinney, B. A., Poland, G. A., and Kennedy, R. B. (2019). The role of systems biology approaches in determining molecular signatures for the development of more effective vaccines. Expert Rev. Vaccines 18, 253-267. doi: 10.1080/14760584.2019.1575208

Plotkin, S. A. (2010). Correlates of protection induced by vaccination. Clin. Vaccine Immunol. 17, 1055-1065. doi: 10.1128/CVI.00131-10

Poland, G. A., Ovsyannikova, I. G., and Kennedy, R. B. (2018). Personalized vaccinology: a review. Vaccine 36, 5350-5357. doi: 10.1016/j.vaccine.2017.07. 062
Pollard, A. J., Finn, A, and Curtis, N. (2017). Non-specific effects of vaccines: plausible and potentially important, but implications uncertain. Arch. Dis. Child. 102, 1077-1081. doi: 10.1136/archdischild-2015-310282

Porpiglia, E., Samusik, N., Van Ho, A. T., Cosgrove, B. D., Mai, T., Davis, K. L., et al. (2017). High-resolution myogenic lineage mapping by single-cell mass cytometry. Nat. Cell Biol. 19, 558-567. doi: 10.1038/ncb 3507

Predoi, C. G., Grigoriu, C., Vladescu, R., and Mihart, A. E. (2015). Placental damages in preeclampsia - from ultrasound images to histopathological findings. J. Med. Life 8, 62-65.

Prevent (2020). Pregnancy Research Ethics for Vaccines, Epidemics, and New Technologies. Available online at: http://vax.pregnancyethics.org/ (accessed January 26, 2020).

Pyzik, M., Sand, K. M., Hubbard, J., Andersen, J., Sandlie, I., and Blumberg, R. (2019). The Neonatal Fc Receptor (FcRn): A Misnomer? Front. Immunol. 10:1540. doi: 10.3389/fimmu.2019.01540

Rastogi, D., Wang, C., Mao, X., Lendor, C., Rothman, P. B., and Miller, R. L. (2007). Antigen-specific immune responses to influenza vaccine in utero. J. Clin. Invest. 117, 1637-1646. doi: 10.1172/JCI29466

Rath, T., Kuo, T. T., Baker, K., Qiao, S. W., Kobayashi, K., Yoshida, M., et al. (2013). The immunologic functions of the neonatal FC receptor for IGG. J. Clin. Immunol. 33, 9-17. doi: 10.1007/s10875-012-9768-y

Reeves, P. M., Sluder, A. E., Paul, S. R., Scholzen, A., Kashiwagi, S., and Poznansky, M. C. (2018). Application and utility of mass cytometry in vaccine development. FASEB J. 32, 5-15. doi: 10.1096/fj.201700325R

Revello, M. G., Lilleri, D., Zavattoni, M., Furione, M., Genini, E., Comolli, G., et al. (2006). Lymphoproliferative response in primary human cytomegalovirus (HCMV) infection is delayed in HCMV TRANSMITTER MOTHers. J. Infect. Dis. 193, 269-276. doi: 10.1086/498872

Rice, T. F., Donaldson, B., Bouqueau, M., Kampmann, B., and Holder, B. (2018). Macrophage- but not monocyte-derived extracellular vesicles induce placental pro-inflammatory responses. Placenta 69, 92-95. doi: 10.1016/j.placenta.2018. 07.011

Rice, T. F., Holder, B., and Kampmann, B. (2020). Antibody glycosylation in pregnancy and in newborns: biological roles and implications. Curr. Opin. Infect. Dis. 33, 225-230. doi: 10.1097/QCO.0000000000000646

Richard, G. (2004). Molecular genetics of the ichthyoses. Am. J. Med. Genet. 131C, 32-44. doi: 10.1002/ajmg.c.30032

Riner, D. K., Ndombi, E. M., Carter, J. M., Omondi, A., Kittur, N., Kavere, E., et al. (2016). Schistosoma mansoni infection can jeopardize the duration of protective levels of antibody responses to immunizations against hepatitis B and Tetanus Toxoid. PLoS Negl. Trop. Dis. 10:e0005180. doi: 10.1371/journal.pntd. 0005180

Rogier, E. W., Frantz, A. L., Bruno, M. E. C., Wedlund, L., Cohen, D. A., Stromberg, A. J., et al. (2015). Lessons from mother: long-term impact of antibodies in breast milk on the gut microbiota and intestinal immune system of breastfed offspring. Gut Microbes 5, 663-668. doi: 10.4161/19490976.2014.96 9984

Rongsen-Chandola, T., Strand, T. A., Goyal, N., Flem, E., Rathore, S. S., Arya, A., et al. (2014). Effect of withholding breastfeeding on the immune response to a live oral rotavirus vaccine in North Indian infants. Vaccine 32, A134-A139. doi: 10.1016/j.vaccine.2014.04.078

Roopenian, D. C., and Akilesh, S. (2007). FcRn: the neonatal Fc receptor comes of age. Nat. Rev. Immunol. 7, 715-725. doi: 10.1038/nri2155

Rowe, J., Yerkovich, S. T., Richmond, P., Suriyaarachchi, D., Fisher, E., Feddema, L., et al. (2005). Th2-associated local reactions to the acellular diphtheria-tetanuspertussis vaccine in 4- to 6-year-old children. Infect. Immun. 73, 8130-8135. doi: 10.1128/IAI.73.12.8130-8135.2005

Rubinstein, F., Micone, P., Bonotti, A., Wainer, V., Schwarcz, A., Augustovski, F., et al. (2013). Influenza A/H1N1 MF59 adjuvanted vaccine in pregnant women and adverse perinatal outcomes: multicentre study. BMJ 346:f393. doi: 10.1136/ bmj.f393

Saadatian-Elahi, M., Aaby, P., Shann, F., Netea, M. G., Levy, O., Louis, J., et al. (2016). Heterologous vaccine effects. Vaccine 34, 3923-3930. doi: 10.1016/j. vaccine. 2016.06.020

Sabin, E. A., Araujo, M. I., Carvalho, E. M., and Pearce, E. J. (1996). Impairment of tetanus toxoid-specific Th1-like immune responses in humans infected with Schistosoma mansoni. J. Infect. Dis. 173, 269-272. doi: 10.1093/infdis/173.1.269 
Sadarangani, S. P., Whitaker, J. A., and Poland, G. A. (2015). "let there be light": the role of Vitamin D in the immune response to vaccines. Expert Rev. Vaccines 14, 1427-1440. doi: 10.1586/14760584.2015.1082426

Steffen, U., Koeleman, C. A., Sokolova, M. V., Bang H., Kleyer, A., Jürgen, R., et al. (2020). IgA subclasses have different effector functions associated with distinct glycosylation profiles. Nat. Commun. 11:120. doi: 10.1038/s41467-019-13992-8

Sage Interim Recommendations on Vaccination against Ebola Virus Disease (2019). Available online at: https://apps.who.int/iris/bitstream/handle/10665/ 276544/WER9349.pdf?ua=1 (Accessed January 23, 2020).

Salk, H. M., Simon, W. L., Lambert, N. D., Kennedy, R. B., Grill, D. E., Kabat, B. F., et al. (2016). Taxa of the nasal microbiome are associated with influenza-specific IgA response to live attenuated influenza vaccine. PLoS One 11:e0162803. doi: 10.1371/journal.pone. 0162803

Saso, A., and Kampmann, B. (2016). Vaccination against respiratory syncytial virus in pregnancy: a suitable tool to combat global infant morbidity and mortality? Lancet Infect. Dis. 16, e153-e163. doi: 10.1016/S1473-3099(16) 00119-5

Saunders, K. O. (2019). Conceptual approaches to modulating antibody effector functions and circulation half-life. Front. Immunol. 10:1296. doi: 10.3389/ fimmu.2019.01296

Schlaudecker, E. P., Steinhoff, M. C., Omer, S. B., McNeal, M. M., Roy, E., Arifeen, S. E., et al. (2013). IgA and neutralizing antibodies to influenza A virus in human milk: a randomized trial of antenatal influenza immunization. PLoS One 8:e70867. doi: 10.1371/journal.pone.0070867

Schleiss, M. R., Permar, S. R., and Plotkin, S. A. (2017). Progress toward development of a vaccine against congenital cytomegalovirus infection. Clin. Vaccine Immunol. 24:e00268-17. doi: 10.1128/CVI.00268-17

Selman, M. H. J., De Jong, S. E., Soonawala, D., Kroon, F. P., Adegnika, A. A., Deelder, A. M., et al. (2012). Changes in antigen-specific IgG1 Fc $\mathrm{N}$-glycosylation upon influenza and tetanus vaccination. Mol. Cell. Proteomics 11:M111.014563. doi: 10.1074/mcp.M111.014563

Sheridan, P. A., Paich, H. A., Handy, J., Karlsson, E. A., Hudgens, M. G., Sammon, A. B., et al. (2012). Obesity is associated with impaired immune response to influenza vaccination in humans. Int. J. Obes. 36, 1072-1077. doi: 10.1038/ijo. 2011.208

Siegrist, C. A. (2003). Mechanisms by which maternal antibodies influence infant vaccine responses: review of hypotheses and definition of main determinants. Vaccine 21, 3406-3412. doi: 10.1016/s0264-410x(03)00342-6

Simister, N. E. (2003). Placental transport of immunoglobulin G. Vaccine 21, 3365-3369. doi: 10.1016/S0264-410X(03)00334-7

Slogrove, A. L., Archary, M., and Cotton, M. F. (2016). Optimizing research methods to understand HIV-exposed uninfected infant and child morbidity: report of the second HEU infant and child workshop. Front. Immunol. 7:576. doi: 10.3389/fimmu.2016.00576

Steedman, M. R., Kampmann, B., Schillings, E., Al Kuwari, H., and Darzi, A. (2016). Strategies to boost maternal immunization to achieve further gains in improved maternal and newborn health. Health Aff. 35, 309-316. doi: 10.1377/hlthaff. 2015.1090

Storsaeter, J., Hallander, H. O., Gustafsson, L., and Olin, P. (2003). Low levels of antipertussis antibodies plus lack of history of pertussis correlate with susceptibility after household exposure to Bordetella pertussis. Vaccine 21, 3542-3549. doi: 10.1016/s0264-410x(03)00407-9

Stubbington, M. J. T., Rozenblatt-Rosen, O., Regev, A., and Teichmann, S. A. (2017). Single-cell transcriptomics to explore the immune system in health and disease. Science 358, 58-63. doi: 10.1126/science.aan6828

Switzer, C., D’Heilly, C., and Macina, D. (2019). Immunological and clinical benefits of maternal immunization against pertussis: a systematic review. Infect. Dis. Ther. 8, 499-541. doi: 10.1007/s40121-019-00264-7

Tarabichi, Y., Li, K., Hu, S., Nguyen, C., Wang, X., Elashoff, D., et al. (2015). The administration of intranasal live attenuated influenza vaccine induces changes in the nasal microbiota and nasal epithelium gene expression profiles. Microbiome 3:74. doi: 10.1186/s40168-015-0133-2

Than, N. G., Hahn, S., Rossi, S. W., and Szekeres-Bartho, J. (2019). Editorial: fetal-maternal immune interactions in pregnancy. Front. Immunol. 10:2729. doi: 10.3389/fimmu.2019.02729

Tong, M., and Chamley, L. W. (2015). Placental extracellular vesicles and fetomaternal communication. Cold Spring Harb. Perspect Med. 5:a023028. doi: 10.1101/cshperspect.a023028
Toscano, M., De Grandi, R., Grossi, E., and Drago, L. (2017). Role of the human breast milk-associated microbiota on the newborns' immune system: a mini review. Front. Microbiol. 8:2100. doi: 10.3389/fmicb.2017.02100

Touzot, F., Dal-Cortivo, L., and Blood, V. V. (2012). Massive expansion of maternal $\mathrm{T}$ cells in response to EBV infection in a patient with SCID-Xl. Blood 120, 1957-1959.

Tregoning, J. S., Weiner, J., Cizmeci, D., Hake, D., Maertzdorf, J., Kaufmann, S. H. E., et al. (2020). Pregnancy has a minimal impact on the acute transcriptional signature to vaccination. NPJ Vaccines 5, 1-11. doi: 10.1038/ s41541-020-0177-6

Tsai, T., Kyaw, M. H., Novicki, D., Nacci, P., Rai, S., and Clemens, R. (2010). Exposure to MF59-adjuvanted influenza vaccines during pregnancyA retrospective analysis. Vaccine 28, 1877-1880. doi: 10.1016/j.vaccine.2009.11. 077

Turco, M. Y., and Moffett, A. (2019). Development of the human placenta. Development 146:dev163428. doi: 10.1242/dev.163428

Turco, M. Y., Gardner, L., Kay, R. G., Hamilton, R. S., Prater, M., Hollinshead, M. S. et al. (2018). Trophoblast organoids as a model for maternal-fetal interactions during human placentation. Nature 564, 263-267. doi: 10.1038/s41586-0180753-3

Twisselmann, N., Bartsch, Y. C., Pagel, J., Wieg, C., Hartz, A., Ehlers, M., et al. (2018). IgG Fc glycosylation patterns of preterm infants differ with gestational age. Front. Immunol. 9:3166. doi: 10.3389/fimmu.2018.03166

UN News (2019). Pregnant, Nursing Women Can Now be Given Ebola Vaccine, UN Health Agency Announces. Available online at: https://news.un.org/en/story/ 2019/02/1033281

Uthayakumar, D., Paris, S., Chapat, L., Freyburger, L., Poulet, H., and De Luca, K. (2018). Non-specific effects of vaccines illustrated through the BCG example: from observations to demonstrations. Front. Immunol. 9:2869. doi: 10.3389/ fimmu.2018.02869

Van De Perre, P. (2003). Transfer of antibody via mother's milk. Vaccine 21, 3374-3376. doi: 10.1016/S0264-410X(03)00336-0

van den Berg, J. P., Westerbeek, E. A. M., Berbers, G. A. M., van Gageldonk, P. G. M., van der Klis, F. R. M., and van Elburg, R. M. (2010). Transplacental transport of IgG antibodies specific for pertussis, diphtheria, tetanus, Haemophilus influenzae type b, and Neisseria meningitidis serogroup C is lower in preterm compared with term infants. Pediatr. Infect. Dis. J. 29, 801-805. doi: 10.1097/inf.0b013e3181dc4f77

van den Berg, J. P., Westerbeek, E. A. M., van der Klis, F. R. M., Berbers, G. A. M., and Van Elburg, R. M. (2011). Transplacental transport of IgG antibodies to preterm infants: a review of the literature. Early Hum. Dev. 87, 67-72. doi: 10.1016/j.earlhumdev.2010.11.003

Vestrheim, A. C., Moen, A., Egge-Jacobsen, W., Reubsaet, L., Halvorsen, T. G., Bratlie, D. B., et al. (2014). A pilot study showing differences in glycosylation patterns of igg subclasses induced by pneumococcal, meningococcal, and two types of influenza vaccines. Immun. Inflamm. Dis. 2, 76-91. doi: 10.1002/iid3. 22

Viall, C. A., Chen, Q., Liu, B., Hickey, A., Snowise, S., Salmon, J. E., et al. (2013). Antiphospholipid antibodies internalised by human syncytiotrophoblast cause aberrant cell death and the release of necrotic trophoblast debris. J. Autoimmun. 47, 45-57. doi: 10.1016/j.jaut.2013. 08.005

Victora, C. G., Requejo, J. H., Barros, A. J. D., Berman, P., Bhutta, Z., Boerma, T., et al. (2016). Countdown to 2015: a decade of tracking progress for maternal, newborn, and child survival. Lancet 387, 2049-2059. doi: 10.1016/S01406736(15)00519-X

Vidarsson, G., Dekkers, G., and Rispens, T. (2014). IgG subclasses and allotypes: from structure to effector functions. Front. Immunol. 5:520. doi: 10.3389/ fimmu.2014.00520

Vilajeliu, A., Goncé, A., López, M., Costa, J., Rocamora, L., Ríos, J., et al. (2015). Combined tetanus-diphtheria and pertussis vaccine during pregnancy: Transfer of maternal pertussis antibodies to the newborn. Vaccine 33, 1056-1062. doi: 10.1016/j.vaccine.2014.12.062

Vono, M., Eberhardt, C. S., Auderset, F., Mastelic-Gavillet, B., Lemeille, S., Christensen, D., et al. (2019). Maternal antibodies inhibit neonatal and infant responses to vaccination by shaping the early-life B cell repertoire within germinal centers. Cell Rep. 28, 1773-1784.e5. doi: 10.1016/j.celrep.2019. 07.047 
Voysey, M., Pollard, A. J., Sadarangani, M., and Fanshawe, T. R. (2017). Prevalence and decay of maternal pneumococcal and meningococcal antibodies: a metaanalysis of type-specific decay rates. Vaccine 35, 5850-5857. doi: 10.1016/j. vaccine.2017.09.002

Wales, D. P., Khan, S., Suresh, D., Ata, A., and Morris, B. (2020). Factors associated with Tdap vaccination receipt during pregnancy: a cross-sectional study. Public Health 179, 38-44. doi: 10.1016/j.puhe.2019.10.001

Wanlapakorn, N., Maertens, K., Vongpunsawad, S., Puenpa, J., Tran, T. M. P., Hens, N., et al. (2019). Quantity and quality of antibodies after acellular versus whole-cell Pertussis vaccines in infants born to mothers who received tetanus, diphtheria, and Acellular pertussis vaccine during pregnancy: a randomized trial. Clin. Infect. Dis. doi: 10.1093/cid/ciz778 [Epub ahead of print].

Weinberg, A., Lindsey, J., Bosch, R., Persaud, D., Sato, P., Ogwu, A., et al. (2018). $\mathrm{B}$ and $\mathrm{T}$ cell phenotypic profiles of African HIV-infected and HIV-exposed uninfected infants: associations with antibody responses to the pentavalent rotavirus vaccine. Front. Immunol. 8:2002. doi: 10.3389/fimmu.2017.02002

Wesumperuma, H. L., Perera, A. J., Pharoah, P. O. D., and Hart, C. A. (1999). The influence of prematurity and low birthweight on transplacental antibody transfer in Sri Lanka. Ann. Trop. Med. Parasitol. 93, 169-177. doi: 10.1080/ 00034983.1999.11813407

Wheatley, A. K., Kristensen, A. B., Lay, W. N., and Kent, S. J. (2016). HIVdependent depletion of influenza-specific memory B cells impacts B cell responsiveness to seasonal influenza immunisation. Sci. Rep. 6:26478. doi: 10 . 1038/srep26478

WHO GBS vaccine research development technical roadmap (2020). WHO Preferred Product Characteristics. Available online at: https://www.who.int/ immunization/research/development/ppc_groupb_strepvaccines/en/ (accessed January 26, 2020).

WHO: Global Advisory Committee on Vaccine Safety (2014). Safety of Immunization During Pregnancy: A Review of the Evidence. Available online at: www.who.int (accessed January 30, 2020).

Wilcox, C. R., Holder, B., and Jones, C. E. (2017). Factors affecting the FcRn-mediated transplacental transfer of antibodies and implications for vaccination in pregnancy. Front. Immunol. 8:1294. doi: 10.3389/fimmu.2017. 01294

Wilcox, C. R., and Jones, C. E. (2018). Beyond passive immunity: Is there priming of the fetal immune system following vaccination in pregnancy and what are the potential clinical implications? Front. Immunol. 9:1548. doi: 10.3389/fimmu. 2018.01548

Wilk, M. M., and Mills, K. H. G. (2018). CD4 TRM cells following infection and immunization: implications for more effective vaccine design. Front. Immunol. 9:1860. doi: 10.3389/fimmu.2018.01860

Winter, K., Cherry, J. D., and Harriman, K. (2017). Effectiveness of prenatal tetanus, diphtheria, and acellular pertussis vaccination on pertussis severity in infants. Clin. Infect. Dis. 64, 9-14. doi: 10.1093/cid/ciw633

World Health Organization (2011). Vaccines against tick-borne encephalitis: WHO position paper - Recommendations. Vaccine 29, 8769-8770. doi: 10.1016/j. vaccine.2011.07.024

World Health Organization (2015). Vaccines and vaccination against yellow fever: WHO Position Paper, June 2013-Recommendations. Vaccine 33, 76-77. doi: 10.1016/j.vaccine.2014.05.040

World Health Organization (2016a). Hepatitis E vaccine: WHO position paper, May 2015 - Recommendations. Vaccine 34, 304-305. doi: 10.1016/j.vaccine. 2015.07.056

World Health Organization (2016b). Pertussis vaccines: WHO position paper, August 2015-Recommendations. Vaccine 34, 1423-1425. doi: 10.1016/j.vaccine. 2015.10.136
World Health Organization (2018a). Cholera vaccine: WHO position paper, August 2017 - Recommendations. Vaccine 36, 3418-3420. doi: 10.1016/j. vaccine.2017.09.034

World Health Organization (2018b). Rabies vaccines: WHO position paper, April 2018 - Recommendations. Vaccine 36, 5500-5503. doi: 10.1016/j.vaccine.2018. 06.061

World Health Organization (2018c). Tetanus vaccines: WHO position paper, February 2017 - Recommendations. Vaccine 36, 3573-3575. doi: 10.1016/j. vaccine.2017.02.034

World Health Organization (2018d). WHO position paper, meningococcal a conjugate vaccine: updated guidance, February 2015. Vaccine 36, 3421-3422. doi: 10.1016/j.vaccine.2017. 07.063

World Health Organization (2020). WHO Recommends Seasonal Influenza Vaccination to Pregnant Women as the Highest Priority. Available online at: https://www.who.int/immunization/newsroom/newsstory_ seasonal_influenza_vaccination_pregnancy/en/ (accessed January 23, 2020).

Wu, D., Lewis, E. D., Pae, M., and Meydani, S. N. (2019). Nutritional modulation of immune function: analysis of evidence, mechanisms, and clinical relevance. Front. Immunol. 10:3160. doi: 10.3389/fimmu.2018.03160

Zaman, K., Roy, E., Arifeen, S. E., Rahman, M., Raqib, R., Wilson, E., et al. (2008). Effectiveness of maternal influenza immunization in mothers and infants. N. Engl. J. Med. 359, 1555-1564. doi: 10.1056/NEJMoa070 8630

Zhang, Y., Meyer-Hermann, M., George, L. A., Figge, M. T., Khan, M., Goodall, M., et al. (2013). Germinal center B cells govern their own fate via antibody feedback. J. Exp. Med. 210, 457-464. doi: 10.1084/jem.2012 0150

Zhivaki, D., and Lo-Man, R. (2017). In utero development of memory $\mathrm{T}$ cells. Semin. Immunopathol. 39, 585-592. doi: 10.1007/s00281-0170650-0

Zimmermann, P., and Curtis, N. (2018). The influence of the intestinal microbiome on vaccine responses. Vaccine 36, 4433-4439. doi: 10.1016/j.vaccine.2018.04. 066

Zimmermann, P., and Curtis, N. (2019). Factors that influence the immune response to vaccination. Clin. Microbiol. Rev. 32:e00084-18. doi: 10.1128/CMR. 00084- 18

Zimmerman, P., Perrett, K. P., Messina, N. L., Donath, S., Ritz, N, van der Klis, F. R. M., et al. (2019). The Effect of maternal immunisation during pregnancy on infant vaccine responses. E Clin. Med. 13, 21-30. doi: 10.1016/j.eclinm.2019.06. 010

Conflict of Interest: BK's institution receives funding from a variety of donors, including industry for the conduct of vaccine-related research in women and children.

The remaining author declares that the research was conducted in the absence of any commercial or financial relationships that could be construed as a potential conflict of interest.

Copyright (C) 2020 Saso and Kampmann. This is an open-access article distributed under the terms of the Creative Commons Attribution License (CC BY). The use, distribution or reproduction in other forums is permitted, provided the original author(s) and the copyright owner(s) are credited and that the original publication in this journal is cited, in accordance with accepted academic practice. No use, distribution or reproduction is permitted which does not comply with these terms. 